\title{
Election uncertainty, economic policy uncertainty and financial market uncertainty: A prediction market analysis
}

\author{
John W. Goodell ${ }^{a, *}$, Richard J. McGee ${ }^{b}$, Frank McGroarty ${ }^{c}$ \\ ${ }^{a}$ College of Business Administration, University of Akron \\ email: johngoo@uakron.edu \\ ${ }^{b}$ Smurfit Graduate Business School, University College Dublin, Ireland \\ email: richard.mcgee@ucd.ie \\ ${ }^{c}$ Centre for Digital Finance, Southampton Business School, University of Southampton, Southampton, \\ SO17 1BJ, United Kingdom \\ email:f.j.mcgroarty@soton.ac.uk
}

\begin{abstract}
We examine the relationship between election uncertainty, economic policy uncertainty, and financial market uncertainty in a prediction-market analysis, covering seven US presidential election campaigns. We argue theoretically that changes in the incumbent party re-election probability should be a key driver of changes in policy uncertainty. Consistent with this theory, we find that a large portion of changes in financial uncertainty in the final stages of election campaign seasons is explained by changes in the probability of the incumbent party getting re-elected. Our findings suggest that the incumbent-party election probability, derived from prediction markets, is an important measure of economic policy uncertainty in the days leading up to US elections.
\end{abstract}

Keywords: Political uncertainty; Economic policy uncertainty; Financial uncertainty;

Election uncertainty; Prediction markets

JEL: E65, G10, G13, G18

${ }^{*}$ The authors are grateful to the managing editor, and three anonymous reviewers; as well as A Aloosh, MH Gagnon, and participants in the 2017 INFINITI Conference on International Finance (València) for helpful suggestions, but remain responsible for any errors. 


\title{
Election uncertainty, economic policy uncertainty and financial market uncertainty: A prediction market analysis
}

\begin{abstract}
We examine the relationship between election uncertainty, economic policy uncertainty, and financial market uncertainty in a prediction-market analysis, covering seven US presidential election campaigns. We argue theoretically that changes in the incumbent party re-election probability should be a key driver of changes in policy uncertainty. Consistent with this theory, we find that a large portion of changes in financial uncertainty in the final stages of election campaign seasons is explained by changes in the probability of the incumbent party getting re-elected. Our findings suggest that the incumbent-party election probability, derived from prediction markets, is an important measure of economic policy uncertainty in the days leading up to US elections.

Keywords: Political uncertainty; Economic policy uncertainty; Financial uncertainty; Election uncertainty; Prediction markets

JEL: E65, G10, G13, G18
\end{abstract}

\section{Introduction}

We investigate how election uncertainty, measured directly from prediction markets, impacts policy uncertainty and financial uncertainty. Pástor and Veronesi (2013) propose a policy uncertainty channel to explain how political uncertainty impacts on market uncertainty. They apply the economic policy uncertainty (EPU) measure of Baker et al. (2016) in empirical analysis, subsequently evidencing support for their theoretical model. While Pástor and Veronesi (2013) highlight the importance of EPU on financial uncer- 
tainty, it is not clear how election uncertainty impacts EPU and financial uncertainty. In order to examine the role of election uncertainty, we measure election uncertainty (EU) directly as a separate variable to EPU. We then consider the impact of daily changes in outcome probabilities and election uncertainty in the run up to US presidential elections on economic policy uncertainty and financial market uncertainty. Towards this end, we use a panel vector autoregressive (VAR) system which includes both election uncertainty, EPU, and two measures of financial uncertainty. We analyze the system using Granger causation analysis, impulse response analysis, and forecast error variance decomposition (FEVD). As measures of election uncertainty, we use daily futures prices from US presidential election prediction markets around seven US elections. To capture financial market uncertainty, we use a conditional variance forecast model from Bekaert and Hoerova (2014), and also use this measure to extract a variance premium variable from the VIX.

Our main finding is that changes in the election probability of the party of incumbency have a dominant role in how election uncertainty impacts both a leading measure of policy uncertainty and financial uncertainty.

We consider our research design and concomitant findings provide an important contribution alongside previous studies. In addition to Pástor and Veronesi (2013), there have been a number of studies on election uncertainty. For instance, Knight (2006) and Mattozzi (2008) consider the impact of daily changes in election-outcome probabilities on daily changes in stock prices through a partisan lens, whereby differing candidate policies are expected to benefit individual companies or industries. Other research examines the impact of election uncertainty on market volatility. For instance, Goodell and Vähämaa (2013) look at the impact of election uncertainty on implied volatility at the monthly 
level. More recently, Kelly et al. (2016) measure the impact of political uncertainty in an event study using a range of options measures.

Our contribution relative to existing work is that we measure the level of election uncertainty directly from daily prediction markets and perform analysis at the daily frequency in the run up to US presidential elections. This allows us to construct a system panel VAR with the daily variables of interest. We use daily data from Monday on the week before the election through to the Wednesday after the election (eight trading days) for seven US elections covering the period $1992-2016{ }^{1}$

We hypothesize that under the theoretical model of Pástor and Veronesi (2013), all else being equal, changes in election uncertainty should impact policy uncertainty through the risk of an incumbent party (whose recent policies presumably are known by the electorate) being replaced with a non-incumbent party (with higher associated policy uncertainty). Our empirical results support this expectation with forecast error variance decomposition analysis showing that changes to the incumbent party probability explain $48 \%$ of the variation in changes to financial uncertainty and $26 \%$ of the changes to economic policy uncertainty (as measured by the index of Baker et al., 2016) in the final days before US elections. This contrasts starkly with what we find for a non-partisan uncertainty measure. In this latter case, the explanatory power of election uncertainty drops considerably with only $4 \%$ of the changes to EPU and $8 \%$ of the changes to financial uncertainty explained by changes in non-partisan election uncertainty.

Further, from our analysis it is clear that changes in the incumbent party probability of victory are statistically significant in Granger causing both economic policy uncertainty and financial uncertainty. These results should be of interest to scholars interested in the

\footnotetext{
${ }^{1}$ We also consider variations of this time period for robustness, see Appendix C.
} 
information content of prediction markets, in measuring policy uncertainty and in the impact of election uncertainty. They may also be of interest to participants in options markets or volatility traders in the lead up to US Presidential elections. ${ }^{2}$

\section{Prediction market analysis}

Recently, a number of studies investigating election uncertainty have integrated time series data from prediction markets into quasi event-study frameworks. Snowberg et al. (2011) describe the benefits of combining prediction-market data with an event-studies approach. The reasoning behind this approach is that each prediction market probability change can be treated as an event in its own right, with the impact on other variables concomitantly being examinable across a much larger sample than a single event study. A potential drawback of this type of analysis is that there may be endogeneity issues. Therefore, care is warranted in interpreting results. An example is given in Snowberg et al. (2011). They initially consider an "Obama Slump" highlighted in the financial press. This slump regarded a negative correlation between Obama's chances of winning and the stock market. However, the authors find that this correlation was far more likely due to a declining economy that was hurting both the stock market and McCain's chance of election.

We use daily data in the run up to US presidential elections to perform structural analysis on the relation between election uncertainty, economic policy uncertainty, and two measures of market uncertainty. Our use of prediction market data increases the sample size available for each election to investigate the effect of innovations to election uncertainty and changes in other uncertainty variables at the business end of US election

\footnotetext{
${ }^{2}$ We discuss economic significance in more detail in Section 7.6.
} 
campaigns.

If market participants are sensitive to the likelihoods of differing election outcomes, it is more plausible that they consequently will hold differing positions as hedges against differing alternative outcomes, than it is that they will hold static positions or wait until after the election to hedge or adjust their respective positions. It is reasonable to consider that investors will incrementally respond to changes in expected election outcomes and there is empirical evidence of this in the aforementioned studies looking at the impact of election uncertainty on individual equities. While a traditional event study would capture the aggregate movement over an election event window, it could potentially miss the additional information contained in changes driven by individuals adjusting their portfolios during an election campaign. We consider that our use of prediction market data will provide a higher resolution of information toward identifying relationships between variables of interest around elections.

We base our analysis on a time series framework designed for the structural analysis of endogenous variables, namely a VAR system. In order to interpret impulse response functions (IRFs) and perform FEVD analysis, we need to identify the system by specifying the ordering of the variables. This is commonly done by first ordering the variables in order of exogeneity and then restructuring using Cholesky decomposition to isolate the effect of shocks to individual error terms. We follow a common approach to the selection (identifying) of exogenous variables by justifying a priori restrictions. However, in this study, as with others of a similar nature, it is not practical to fully address this issue of endogeneity within the data set and framework. Causality in both directions is plausible for the relationship between any of the pairings of our uncertainty variables. ${ }^{3}$

\footnotetext{
${ }^{3}$ Snowberg et al. (2007) highlight a natural experiment to analyze impact of polls closely concurrent to elections, but before votes are actually counted. In this scenario, the channel from the economy back
} 
Figure 1 and Table 1 illustrate the full set of candidate causality paths between the four uncertainty variables used in our study. As illustrated in this figure and table, there are challenges and ambiguities with identifying a priori assumptions, as causality between pairs of our variables could theoretically flow in either direction. We therefore seek to infer causality with other analysis. ${ }^{4}$ To inform an ordering of our uncertainty variables, we perform Granger causality analysis on the VAR system, a procedure which does not require identifying restrictions. First, the lag order of the system is selected based on maximum likelihood estimation. Subsequently, from the resulting model we can perform Granger causality analysis between pairs of the variables and also test the extent to which a variable is Granger caused by all other variables. The variables are then ordered in increasing magnitude of endogeneity based on this analysis. Crucially, in order to add validity to the interpretation of our results, robustness tests are run on alternative VAR orderings to ensure that our results are robust to the ordering of the VAR identification.

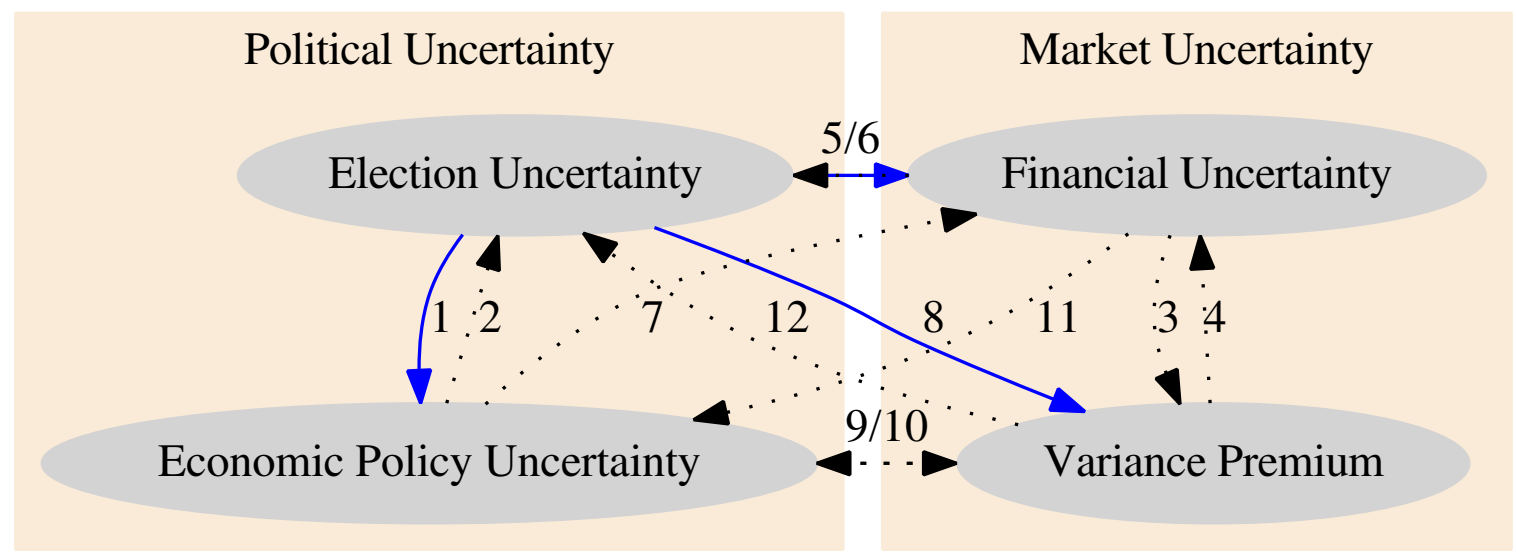

Figure 1: Illustration of all of the possible causality paths among our four uncertainty variables: Election Uncertainty (EU); Economic Policy Uncertainty (EPU); Financial Uncertainty (FU) and the Variance Premium (VP). Descriptions of the numbered causality paths are given in Table 1.

to the election outcome, is closed, leaving only causality from election uncertainty to the market.

${ }^{4}$ An early pioneer, Sims (1972) uses Granger causality analysis to demonstrate the causal priority of money over nominal income. Sims (1981) suggests investigating the sensitivity of results to reordering of the variables: if results are robust to orderings then it is possible to draw conclusions without full identification of the system. 


\begin{tabular}{|c|c|c|}
\hline $\begin{array}{l}\text { Causality } \\
\text { Path }\end{array}$ & Description & Potential Drivers of Causation \\
\hline 1. & $\mathrm{EU}->\mathrm{EPU}$ & $\begin{array}{l}\text { Competing election candidates have different associated political } \\
\text { costs around government policy decisions }\left(c_{R E P}^{n} \text { and } c_{D E M}^{n} \text { in Sec- }\right. \\
\text { tion 3.3), driving uncertainty about their policy decisions. Changes } \\
\text { in uncertainty about their relative chances of election success cause } \\
\text { changes in the resulting expectation of policy uncertainty. }\end{array}$ \\
\hline 2. & $\mathrm{EPU}->\mathrm{EU}$ & $\begin{array}{l}\text { External drivers of policy uncertainty may favor a candidate, for } \\
\text { example an incumbent may be penalized for poor economic condi- } \\
\text { tions that drive increased policy uncertainty. }\end{array}$ \\
\hline 3. & $\mathrm{FU}->\mathrm{VP}$ & $\begin{array}{l}\text { Changes in market volatility cause changes in crash risk percep- } \\
\text { tions or crash risk premia as increased volatility is associated with } \\
\text { negative tail events. }\end{array}$ \\
\hline 4. & $\mathrm{VP}->\mathrm{FU}$ & $\begin{array}{l}\text { Changes in the level of negative tail event probability or crash risk } \\
\text { premia lead to changes in market volatility. }\end{array}$ \\
\hline 5. & $\mathrm{EU}->\mathrm{FU}$ & $\begin{array}{l}\text { Changes in election uncertainty cause changes in market volatility } \\
\text { as market prices adjust between two valuations based on expecta- } \\
\text { tions using the two future presidential political costs. }\end{array}$ \\
\hline 6. & $\mathrm{FU}->\mathrm{EU}$ & $\begin{array}{l}\text { Changes in financial uncertainty cause changes in election uncer- } \\
\text { tainty as the relative prospects of candidates are influenced by mar- } \\
\text { ket conditions (for example, an incumbent candidate or party may } \\
\text { be penalized for poor economic performance). }\end{array}$ \\
\hline 7. & $\mathrm{EPU}->\mathrm{FU}$ & $\begin{array}{l}\text { Changes in policy uncertainty cause changes in market volatility } \\
\text { (see Pástor and Veronesi, 2013). }\end{array}$ \\
\hline 8. & $\mathrm{FU}->\mathrm{EPU}$ & $\begin{array}{l}\text { Changes in financial uncertainty cause changes in policy uncertainty } \\
\text { as candidates are more likely to change policies perceived to be } \\
\text { failing. }\end{array}$ \\
\hline 9. & EPU -> VP & $\begin{array}{l}\text { Changes in policy uncertainty cause changes in market crash } \\
\text { risk/fears. }\end{array}$ \\
\hline 10. & $\mathrm{VP}->\mathrm{EPU}$ & $\begin{array}{l}\text { Changes in crash risk perceptions cause changes in economic policy } \\
\text { uncertainty, for example in poor economic conditions a change in } \\
\text { policy has increased likelihood. }\end{array}$ \\
\hline 11. & $\mathrm{FU}->\mathrm{EPU}$ & $\begin{array}{l}\text { Changes in financial uncertainty cause changes in economic policy } \\
\text { uncertainty as candidates are more likely to change policies per- } \\
\text { ceived to be failing. }\end{array}$ \\
\hline 12. & $\mathrm{VP}->\mathrm{EU}$ & $\begin{array}{l}\text { Changes in crash risk perceptions cause changes in election un- } \\
\text { certainty as the relative prospects of candidates are influenced by } \\
\text { market conditions (for example, an incumbent candidate or party } \\
\text { may be penalized for poor economic performance). }\end{array}$ \\
\hline
\end{tabular}

Table 1: Description of the possible causality paths illustrated in Figure 1.

\section{Description of causality channels}

In this section we discuss the channels through which election outcome uncertainty may affect policy uncertainty and financial market uncertainty.

\subsection{Political uncertainty and financial uncertainty}

Asset volatility, by definition, is caused by changing asset prices. There has been widespread ongoing interest for many years as to what drives those changes and as to why volatility increases in certain periods such as bear market regimes and around political 
events. In the context of political uncertainty, Pástor and Veronesi (2013) propose a model in which stock-price changes are driven by three different channels: economic shocks (subdivided into capital and impact shocks), firm-specific shocks, and shocks to political uncertainty. Political uncertainty, being undiversifiable, therefore commands a risk premium and their model implies that its magnitude is larger in weaker economic conditions.

In the Pástor and Veronesi (2013) model, the government makes policy decisions to maximize a utility function that is aligned with that of investors but is scaled by a political cost function that represents the political cost to the government of making a policy choice. Therefore, government policy may diverge from the utility maximizing decision of an investor if the political cost of the policy decision is too high.

In this paper we look at how election uncertainty impacts the uncertainty around policy choice. Under the Pástor and Veronesi (2013) model election uncertainty should impact on financial market uncertainty via its impact on policy uncertainty. The uncertainty around the political cost of implementing a given policy may vary across two candidate future governments. It is uncertainty around this cost that drives political uncertainty and the political uncertainty premium in their model.

\subsection{Election uncertainty and economic policy uncertainty}

Under the Pástor and Veronesi (2013) model, political uncertainty is broadly defined as uncertainty about government actions. This is driven by uncertainty about the political costs associated with any given policy choice, as these costs directly influence government decisions. Political shocks to asset prices are caused by agents learning about the political costs associated with potential new policies. As information about the political costs associated with a policy is learned by agents over time, it is to be expected that, all else 
equal, there is less uncertainty about the political costs associated with an incumbentparty presidential election candidate. With regard to candidates from incumbent parties, agents have had an opportunity to learn their political costs over (at least) a four-year period while they are in power. We formalize this proposal in the following section using an addition to the Pástor and Veronesi (2013) model to allow for two separate sets of political costs associated with the two main presidential election candidates.

\subsection{Presidential election uncertainty and policy uncertainty}

Under the Pástor and Veronesi (2013) model, agents learn about the political costs $\left\{C^{n}\right\}_{n=1}^{N}$ associated with a set of policy decisions by observing unbiased signals:

$$
d s_{t}^{n}=c^{n} d t+h d Z_{c, t}^{n}, n=1, \ldots, N
$$

These signals capture the flow of news relevant to the costs of each policy $\mathrm{n}$ and $h^{2}$ is the variance of the noise in the political cost signaling around its true value.

If we set $\mathrm{t}=0$ as just after the previous election, and assume that an election occurs at time $\mathrm{T}=4$ years, there are two political cost processes to consider: that of each of two candidates. At time $\mathrm{T}$ these are represented as:

$$
\begin{gathered}
c_{R E P}^{n} \sim N\left(-\frac{1}{2} \sigma_{c R E P}^{2}, \sigma_{c R E P}^{2}\right) \text { for } \mathrm{n}=1, \ldots, \mathrm{N} \\
c_{D E M}^{n} \sim N\left(-\frac{1}{2} \sigma_{c D E M}^{2}, \sigma_{c D E M}^{2}\right) \text { for } \mathrm{n}=1, \ldots, \mathrm{N}
\end{gathered}
$$

Where $c_{R E P}^{n}$ is the political cost of policy n to the Republican party candidate and $c_{D E M}^{n}$ is the political cost of policy $\mathrm{n}$ to the Democrat party candidate. The expected political 
cost uncertainty at a time, $\mathrm{t}$, before the election is given by:

$$
E\left[\sigma_{c}^{2}\right]=p_{R E P}^{t} \times \sigma_{c R E P}^{2}+\left(1-p_{R E P}^{t}\right) \times \sigma_{c D E M}^{2}
$$

where $p_{R E P}$ is the probability of the Republican party candidate winning the election and $p_{D E M}$ is the probability of Democrat party candidate winning. The level of policy uncertainty change associated with a change in outcome probability therefore would depend on the relative magnitude of $\sigma_{c R E P}^{2}$ and $\sigma_{c D E M}^{2}$. If both were of equal magnitude we would not expect changes in election outcome probabilities to impact the level of policy uncertainty.

If we consider that candidate $\mathrm{A}$ is an incumbent and that agents carry out Bayesian updating of the political costs in response to the signals in Equation 1, then we get the posterior variance for the political costs associated with candidate A coming up to the election as:

$$
\hat{\sigma}_{c A, t}^{2}=\frac{1}{\frac{1}{\sigma_{c A}^{2}}+\frac{1}{h^{2}}\left(t-t_{0}\right)}
$$

where $t-t_{0}$ is the 4 preceding years that the incumbent was in power. The Bayesian updated variance for an incumbent, $\hat{\sigma}_{c A, t}^{2}$ is therefore smaller than the variance for the same candidate competing the election as a non-incumbent, $\sigma_{c A}^{2}$, as agents have had four years to learn about the political costs of Candidate A while Candidate A was in office.

Substituting the posterior variance into Equation 4 will give a directional aspect to changes in policy uncertainty in response to changes in outcome probabilities provided that the magnitude of the variance reduction for the incumbent dominates any political cost uncertainty differential between the candidates. 
Under the Pástor and Veronesi (2013) model, stock variance is proportional to a weighted sum of the political cost variance across all possible policy decisions. Increased political cost uncertainty should, therefore, also drive increased market volatility.

\section{Measurement}

In this section we discuss the construction of the four variables used in the VAR: election uncertainty (EU), economic policy uncertainty (EPU), financial uncertainty (FU) and the variance premium (VP).

\subsection{Election uncertainty}

Our election uncertainty variable, is derived from the daily change in the probabilities of success of the presidential candidates. We use daily data defined in the same way as Goodell and Vähämaa (2013). These probabilities are obtained from the Iowa Electronic Markets (IEM) winner-take-all presidential-election contracts. The IEM presidential contracts are essentially futures contracts with the payoff based on the election outcome (Democratic/Republican future), with the market prices of these contracts reflecting the market consensus of the probability of payoff. The prices are bounded to sum to one (ignoring the time value of money) as purchasing both a Republican and a Democratic ticket would entail a certainty of payoff equal to the cost of the portfolio of futures. No arbitrage would indicate that if the Republican ticket costs 60 cents, the Democratic ticket must cost 40 cents, as buying both tickets ensures a payoff of $\$ 1$. These prices therefore reflect a $.6 / .4$ probability split, as the prices of the contracts represent the relative probabilities of the respective candidates winning. As the markets are generally considered speculative markets, rather than standard financial markets used for hedging, we ignore the possibility of a specific investor preference for a payout in either state. We consider 
that deriving probabilities from the IEM, while technically an imperfect approximation, is a very close approximation of election probabilities. Research indicates the presidential election markets are better than polls as predictors (Rhode and Strumpf, 2004; Goodell et al., 2015), and particularly indicates the Iowa prediction market as the best proxy for election probabilities. Prediction markets have failed to predict recent upsets such as the Brexit vote in the UK and the victory of Donald Trump in the 2016 election. This, however, does not negate their efficacy in acting as a proxy for market expectation of the election outcomes, which is what we are concerned with when calculating changes in uncertainty about election outcomes.

One issue with deriving probabilities from the Iowa prediction market is that a riskfree rate equal to zero is assumed. Berg et al. (2008) provide a detailed discussion of the no-arbitrage relations between expected outcomes and the market prices of prediction contracts. The market price of a presidential contract reflects the market's consensus forecast of the winning likelihood of the candidate. At time $t$, the market price of the contract, $P_{t}$, is given by:

$$
P_{t}=\frac{E\left[P_{t}\right]}{(1+k)^{T}}
$$

where $k$ is the sum of the risk-free rate and other risk factors, $t$ is the current date, $T$ is the election date, and $E$ denotes the expectations operator. In the IEM winner-take-all market, the overall sum of payoffs at time $T$ for purchasing both a Republican and a Democratic ticket is a risk-free $\$ 1$. Hence, it can be assumed that $k=0$ :

$$
P_{t}=E\left[P_{t+h}\right]
$$


This implies participants in the market are not investing to receive a risk-free rate but rather are looking to profit from their perception of having a better forecast probability of the election outcome than that implied by the IEM price. Iowa prediction markets have a history of outperforming polls with regard to prediction accuracy. It certainly is reasonable as a starting point to consider that, if the Republican and Democratic tickets are close to $\$ 0.50$, there is more uncertainty regarding the election outcome than if there were a $\$ 0.60 / \$ 0.40$ split. In a linear model of uncertainty, we define election uncertainty according to Goodell and Vähämaa (2013) as follows:

$$
E U^{N P}=1-\mid \text { win }_{i}-\left(1-\operatorname{pwin}_{i}\right) \mid
$$

where $\operatorname{pwin}_{i}$ is the probability of either candidate winning the election.

The uncertainty variable in Equation 8 is a non-partisan measure, it does not indicate whether changes in probability are toward or away from the incumbent party. As noted in Section 3 the probability of re-election of an incumbent should be an important driver of policy uncertainty. To this end, we also consider a simple measure that captures the change in the probability of the incumbent party winning the election, this is referred to in the paper as a partisan election uncertainty measure $\left(E U^{P}\right)$.

\subsection{Economic policy uncertainty}

As our measure of EPU we use the daily index from Baker et al. (2016). ${ }^{5}$ They calculate their daily news-based EPU index based on US newspaper archives from the Access World News NewsBank service. The index is calculated using 10 leading newspapers: USA Today, Miami Herald, Chicago Tribune, Washington Post, Los Angeles Times, Boston

\footnotetext{
${ }^{5}$ Downloaded on April 12018 from http://www.policyuncertainty.com/us_daily.html
} 
Globe, San Francisco Chronicle, Dallas Morning News, New York Times, and Wall Street Journal. Their data spans from 1985 to present and covers all seven elections in our study. The EPU index is calculated as the number of articles that contain at least one term from each of three sets of terms:

1. "economic" or "economy"

2. "uncertain" or "uncertainty"

3. "legislation" or "deficit" or "regulation" or "congress" or "federal reserve" or "white house"

By construction, it is possible to have a false positive, with an article containing one of these terms without containing content relating to policy uncertainty. There would appear to be a risk of an article scoring for a reference to economic uncertainty that is not necessarily driven by political considerations. We address these issues in our VAR by adding an election uncertainty variable drawn from prediction markets to disentangle election uncertainty from the other sources of uncertainty in the EPU variable. The EPU index spanning the seven elections in our study is illustrated in Figure 2. 


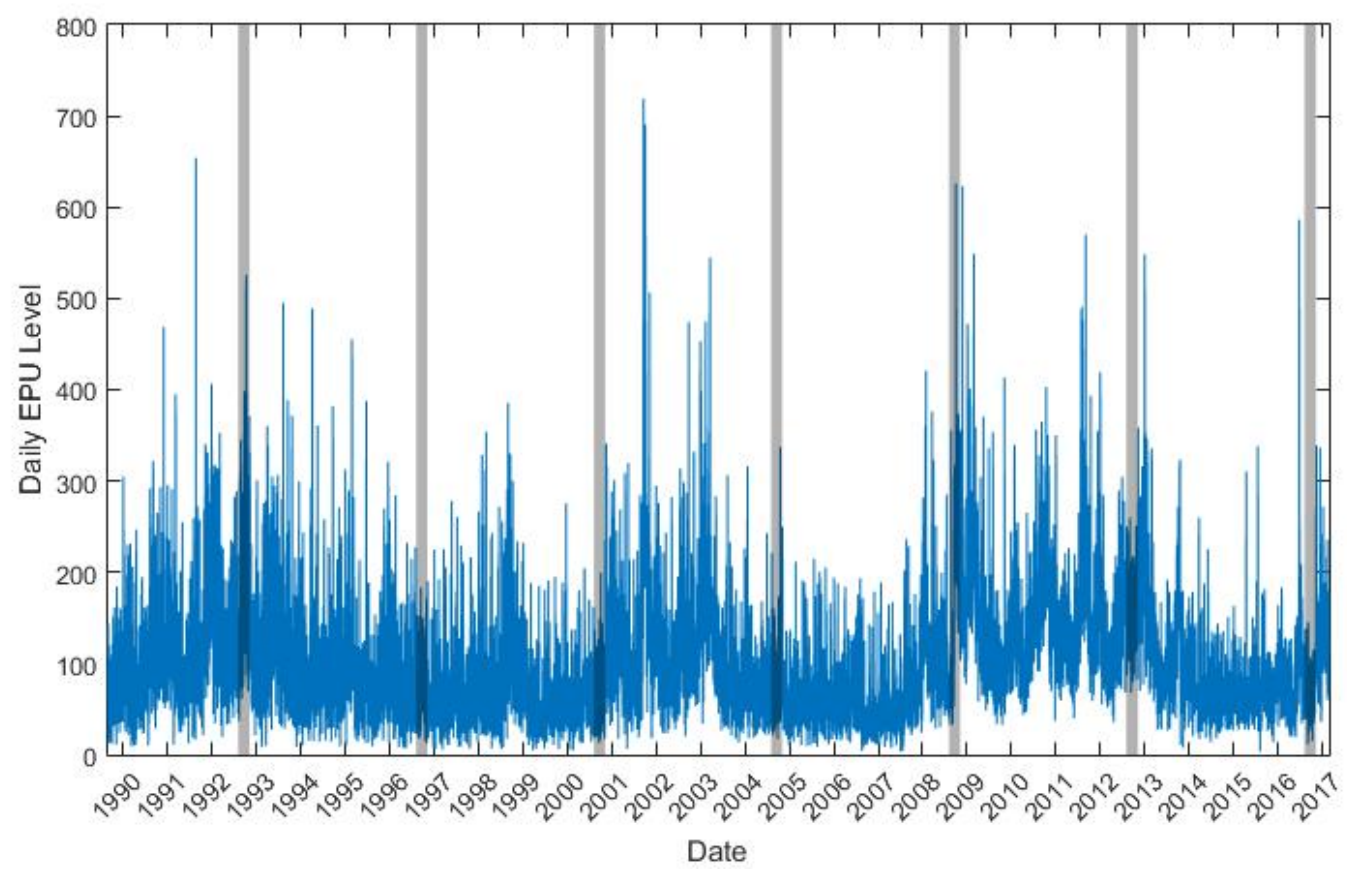

Figure 2: The daily EPU Index level spanning the seven US Presidential elections in our study. The vertical bands highlight the quarter leading up to each election.

\subsection{Financial uncertainty}

As a measure of financial uncertainty we use the conditional variance of market returns. To estimate this, we use the following model from Bekaert and Hoerova $(2014)^{6}$, who test a plethora of conditional variance forecasting models:

$$
R V_{t}^{(22)}=3.730+0.108 V I X_{t-22}^{2}+0.199 R V_{t-22}^{(22)}+0.330 R V_{t-22}^{(5)}+0.107 R V_{t-22}^{(1)} .
$$

This model was selected as one of two best conditional variance estimators. Coefficients are formed from S\&P500-return data for Jan 1990-Oct 2010, which overlaps much of our sample period. ${ }^{7}$

The realized variance $(R V)$, using five-minutely data, is obtained from the Oxford-

\footnotetext{
${ }^{6}$ Model 8 in their paper.

7 We cannot implement the second of the two best models (Model 11) due to data availability as it requires high frequency data implied jump measures.
} 
Man Institute realized-volatility library. ${ }^{8}$ Data are available from January 2000 onwards, covering five of our seven election periods. For the two earliest elections ('92 and '96) we replace high-frequency realized-volatility estimates with values from a Garman and Klass (1980) estimator modified as per Yang and Zhang (2000). This uses open, high, low, and close data points in the volatility estimation that result in improvements over estimates based on daily close-to-close data points alone. A plot of the resulting conditional variance, on a monthly timescale is given in Figure $3 .{ }^{9}$ In our VAR analysis we use the first difference of the $\log$ of the conditional variance (henceforth, $F U=\Delta \log R V_{t}^{(22)}$ ).

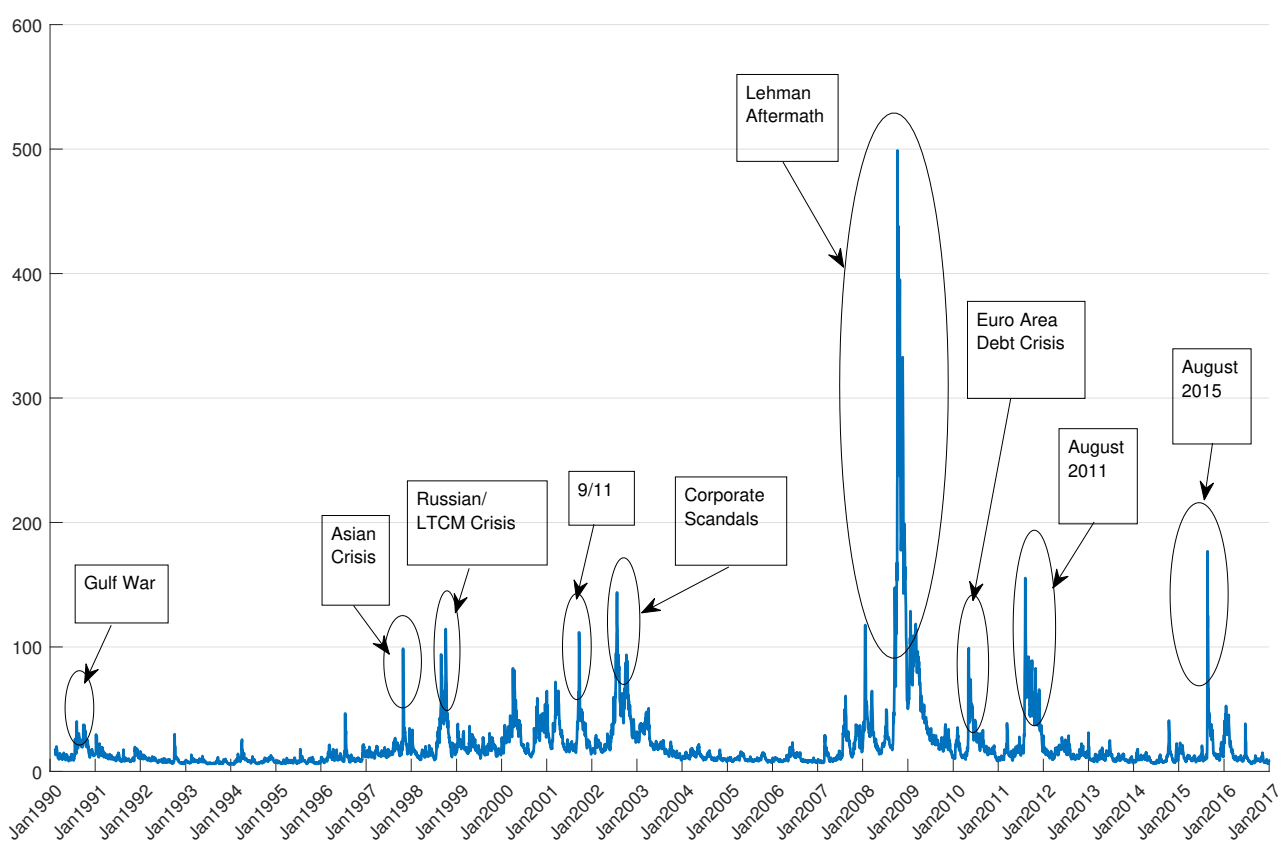

Figure 3: The conditional variance of market returns using Model 8 from Bekaert and Hoerova (2014).

\subsection{The variance premium}

We define the variance premium (VP) as the difference between the expectation of future realized variance under the risk-neutral measure and the expectation under the

\footnotetext{
${ }^{8}$ Available at: http://realized.oxford-man.ox.ac.uk/data

${ }^{9}$ Detailed inspection shows that the plot matches closely with the Model 8 conditional variance in Fig. 1 in Bekaert and Hoerova (2014) for the overlapping time period.
} 
physical measure: ${ }^{10}$

$$
V P(t, \tau)=E^{R N}\left[\sigma^{2}(t, \tau)\right]-E^{P}\left[\sigma^{2}(t, \tau)\right]
$$

where $\tau$ is the expiry date of the options used to calculate the risk-neutral variance. We are interested in volatility over the time range from $t$ to $\tau$. In the case of the VIX, $\tau$ corresponds to a period of 22 trading days from a given closing VIX quote. Following Bekaert and Hoerova (2014), we adopt the square of the VIX as the expected variance under the risk-neutral measure, resulting in the following definition of the VP:

$$
V P_{t}=V I X_{t}^{2}-E\left[R V_{t+1}^{22}\right]
$$

For the $E\left[R V_{t+1}^{22}\right]$ term we use the model in Equation 9 from Bekaert and Hoerova (2014) to forecast the monthly conditional variance of the underlying returns (as described in Section 4.3). A plot of the resulting variance premium, on a monthly timescale is given in Figure 4. In the time series analysis in the paper, we use the first difference of the natural $\log$ of the variance premium (henceforth, $V P=\Delta \log V P_{t}$ ).

The difference between implied and realized volatility is often interpreted as a premium for bearing the volatility risk of an option position, linking the measure to risk aversion (Bekaert et al., 2013; Bekaert and Engstrom, 2017; Bekaert et al., 2019; Longstaff et al., 2011; Martin, 2017; Prokopczuk and Simen, 2014). Drechsler (2013) associates the VP with Knightian uncertainty. According to Knight (1921), there is a fundamental distinction between the reward for taking a known risk and that for assuming a risk whose value itself is not known.

\footnotetext{
${ }^{10} \mathrm{~A}$ common definition adopted in the financial literature on the variance premium see, e.g., Todorov (2009).
} 
Bakshi and Madan (2006) theoretically link the VP to higher moments of the risk neutral distribution. McGee and McGroarty (2017) link the VP with tail risk and the asymmetrical cost to a volatility arbitrageur of volatility forecast errors and show that over-estimation of volatility proves significantly less costly than under-estimation in the presence of Knightian uncertainty about the tails of the underlying return distribution.

While there is an extensive literature with alternative explanations of the variance premium, we assume that the VP is affected by political uncertainty through its impact on uncertainty levels around price jumps, market tail events and/or changes in riskaversion to those events. ${ }^{11}$ The anticipation of election outcome-driven jumps in price levels would increase potential expected losses for an option market maker due to the failed delta hedging of options and might be expected to increase the variance premium demanded by option sellers to take on this additional risk.

\footnotetext{
${ }^{11}$ Due to the joint-hypothesis problem when dealing with risk neutral densities, it is impossible to separate out the subjective probability of an event from preferences related to the event without making questionable assumptions.
} 


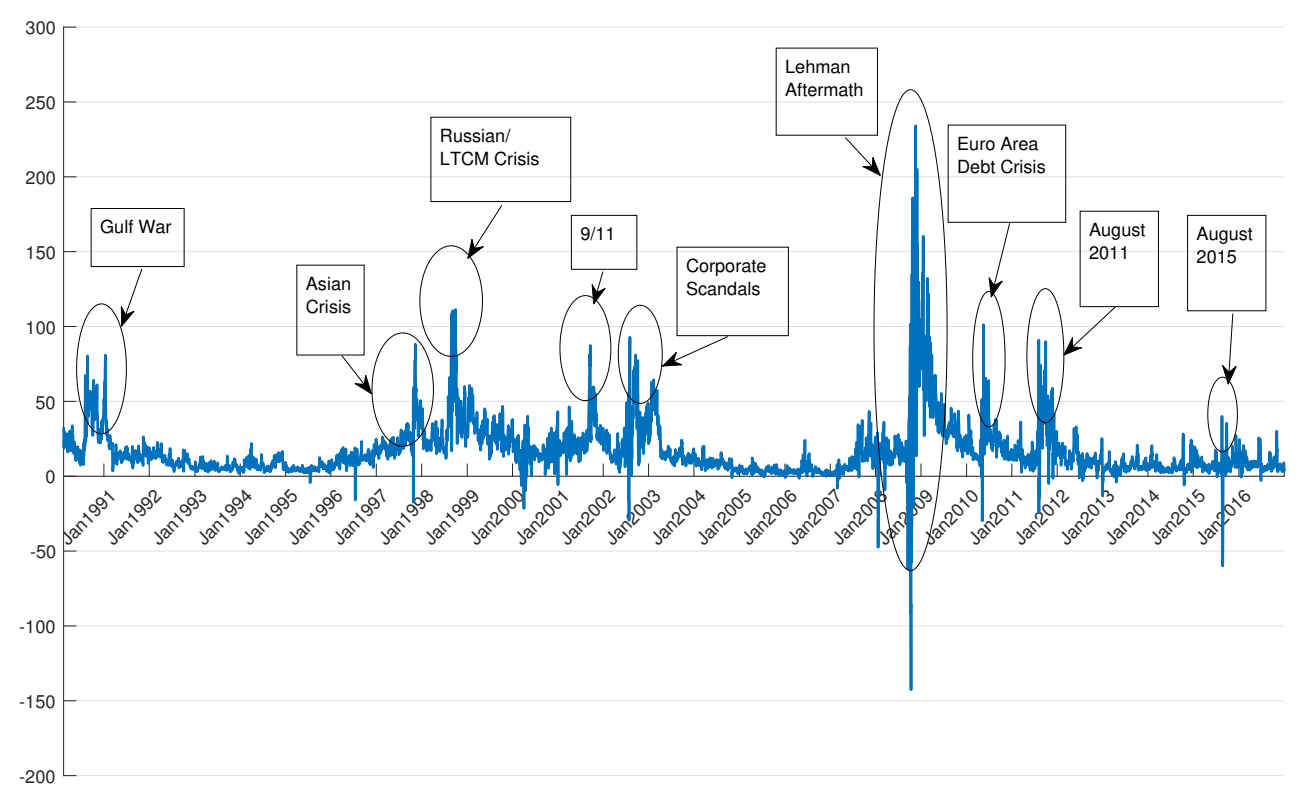

Figure 4: The variance premium estimated by subtracting the variance forecasts in Figure 3 from the $V I X^{2}$

\section{Data}

We consider daily changes in our variables in the lead up to seven US presidential elections (1992, 1996, 2000, 2004, 2008, 2012 and 2016). Changes are taken from Monday on the week before the election through to the Wednesday after the election, this includes election day itself and a further day of trading to capture market reaction to the outcome.

Summary statistics for the four variables used in our analysis are given in Tables 2 and 3. The data include a number of outliers around the 2008 election when the election coincided with the financial market crisis. We do not simply exclude the outliers as the relationship between our variables is of particular interest during difficult market conditions, as emphasized in Pástor and Veronesi (2013). The 2008 election is the only election period in the sample classified as being during a recession by the National Bureau of Economic Research. We deal with outliers by winsorizing all variables to within 2 standard deviations of the sample mean across each election period. 


\begin{tabular}{ccccc}
\hline & mean & std & min & max \\
\hline$E U^{P}$ & 0.01 & 0.16 & -0.65 & 0.76 \\
$E U^{N P}$ & -0.06 & 0.19 & -0.96 & 0.22 \\
$E P U$ & -3.46 & 75.48 & -137.64 & 243.94 \\
$F U$ & -3.06 & 13.84 & -60.12 & 27.01 \\
$V P$ & -2.00 & 26.90 & -185.92 & 55.34 \\
\hline
\end{tabular}

Table 2: Summary statistics for the VAR variables over the whole data set of seven elections $(7 \times 8=56$ days). $E U^{P}$ is the daily change in partisan election uncertainty from Iowa prediction markets; $E U^{N P}$ is the daily change in non-partisan election uncertainty from Iowa prediction markets; $E P U$ is the daily change in the economic policy uncertainty index of Baker et al. (2016); $F U$ is the daily change in the log conditional variance and $V P$ is the daily change in the log variance premium.

We perform an initial analysis on the raw data of our variables of interest to inform the choice of a correct event window in which to examine the impact of variation in election uncertainty as measured from prediction markets. As a basic measure of the impact of election uncertainty in the run up to the elections we examine the weekly average levels for volatility and the variance premium over the seven elections, illustrated in Figure 5. There is clear evidence to suggest a two-week event window with both volatility and the variance risk premium raised in the two weeks before elections. ${ }^{12}$ Our goal in selecting an event window is to pick the longest period possible for statistical inference, while ensuring that the investigated relationships are relevant within the event window at the daily frequency. To this end, we select a window of eight business days, resulting in a sample of 56 data points, spanned by seven two week election event windows. ${ }^{13}$ We test the robustness of our findings to alternative event window periods of shorter and longer duration in Appendix C. We also perform a robustness check on our main results in Appendix B, where we exclude the 2008 election period from our analysis. Our main findings are robust to all of these checks.

\footnotetext{
${ }^{12}$ This window is robust to the exclusion of the 2008 election.

${ }^{13}$ Giving approximately 10 data points per equation coefficient for each VAR equation.
} 
(a.)

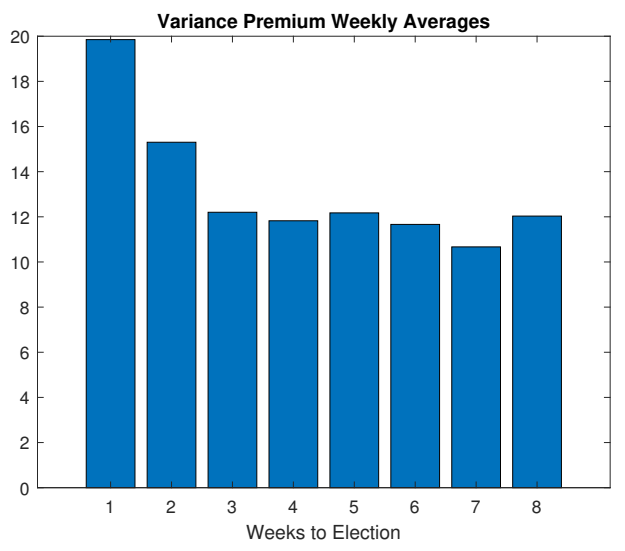

(b.)

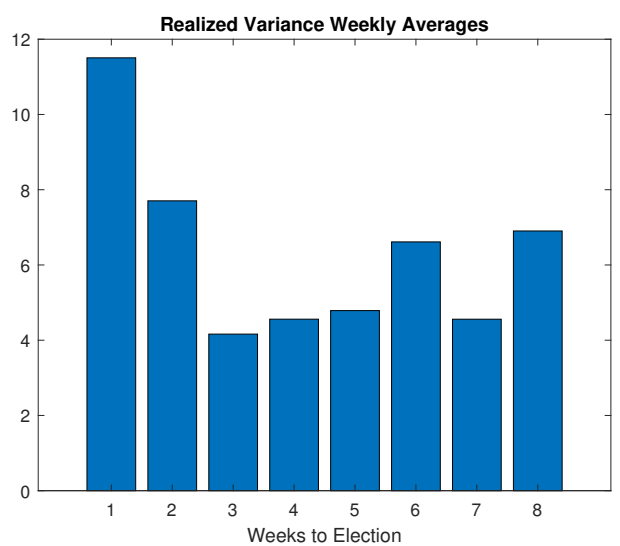

Figure 5: Weekly averages (Wednesday to Wednesday) of realized variance and the variance risk premium, averaged over seven elections. The levels can be seen to rise in the final two weeks before election day, with the largest average levels in the final week before the election.

\begin{tabular}{cccccc}
\hline & $E U^{P}$ & $E U^{N P}$ & $E P U$ & $F U$ & $V P$ \\
\hline$E U^{P}$ & 1.00 & -0.05 & 0.09 & 0.06 & 0.02 \\
$E U^{N P}$ & -0.05 & 1.00 & -0.04 & -0.01 & 0.00 \\
$E P U$ & 0.09 & -0.04 & 1.00 & 0.18 & 0.12 \\
$F U$ & 0.06 & -0.01 & 0.18 & 1.00 & -0.30 \\
$V P$ & 0.02 & -0.00 & 0.12 & -0.30 & 1.00 \\
\hline
\end{tabular}

Table 3: Correlation matrix for the VAR variables over the set of seven elections ( $7 \times 8=56$ days). 


\section{VAR analysis}

We consider two panel VAR specifications, with two alternative variables to capture changes in the election outcome uncertainty. The first VAR includes a non-partisan election uncertainty variable to capture uncertainty about the election outcome: $Z_{i t}=$ $\left[E U_{i t}^{N P} ; E P U_{i t} ; F U_{i t} ; V P_{i t}\right]^{14}$ with the four endogenous variables corresponding to: nonpartisan election uncertainty $\left(E U^{N P}\right)$; economic policy uncertainty $(E P U)$; financial uncertainty $(F U)$ and the variance premium $(V P)$, for election $i$ at time $t$. The second VAR includes partisan election uncertainty $\left(E U^{P}\right)$ to capture uncertainty about the election outcome $Z_{i t}=\left[E U_{i t}^{P} ; E P U_{i t} ; F U_{i t} ; V P_{i t}\right]$. The reduced form dynamic relationship among our endogenous variables can be described by:

$$
Z_{i t}=A_{0 i}+A(l) Z_{t-1}+u_{i t}, \quad i=1, \ldots, 7, \quad t=T-7, \ldots, T+1
$$

where $A_{0 i}$ is a vector of time-invariant election-specific intercepts, $A(l)$ are $4 x 4$ matrices of lagged coefficients that collects the own- and cross-effects of the lag of the dependent variable on their current observations. Finally, $u_{i t}$, is a $4 \mathrm{x} 1$ vector of idiosyncratic disturbances where $E\left[u_{i t}\right]=0, E\left[u_{i t}^{\prime} u_{i t}\right]=\Sigma$ and $E\left[u_{i t}^{\prime} u_{i s}\right]=0$ for all $t>s$.

The VAR systems were estimated using the GMM estimator of Abrigo et al. (2016). For each VAR we select a single lag order VAR, $l=1$, as this was found to be optimal using both Akaike and Schwarz Bayesian information criteria for lag selection. We check the stability condition of panel VAR estimates by calculating the modulus of each eigenvalue of the estimated model. ${ }^{15}$ This criterion is met for each of our estimated VAR models.

\footnotetext{
${ }^{14}$ The ordering of the variables listed does not correspond to the identification ordering of the VAR discussed later.

${ }^{15}$ Lütkepohl (2005) and Hamilton (1994) both show that a VAR model is stable if all moduli of the companion matrix are strictly less than one.
} 
In order to conduct forecast error variance decomposition and impulse response analysis using the estimated VAR models some structural restrictions are required. We use standard Cholesky decomposition of the estimate of the variance-covariance matrix, making the matrix A lower triangular. We order the variables in decreasing order of exogeneity based on the outcome of Granger causality tests on each variable being caused by a combination of the other three variables. The Granger causality paths with statistical significance for the partisan VAR are illustrated in Figure 6. Detailed results and p values are given in Tables 4. The p values reported are for the following hypothesis test:

$H 0$ : Excluded variable does not Granger-cause the equation variable.

$H 1$ : Excluded variable Granger-causes the equation variable.

\section{Results}

\subsection{Model selection}

In this investigation, we use alternatively two differing measures of election uncertainty, corresponding to a partisan uncertainty measure, $E U^{P}$, which is changes in the probability of the candidate who is from the same party as the incumbent president, and a nonpartisan measure of uncertainty, $E U^{N P}$, that treats changes in uncertainty the same regardless of which candidate is gaining or losing in probability. For both panel VAR systems a single lag is selected as optimal based on the three-model selection criteria of Andrews and Lu (2001).

\subsection{Granger causality tests}

We order the respective VAR variables by decreasing exogeneity according to the $\chi^{2}$ value obtained in a Granger causality test on that variable being caused by all of the other 
variables in the system (see Table 4). For the non-partisan election uncertainty VAR the obtained ordering is: $V P->F U->E U^{N P}->E P U$. For the partisan election uncertainty VAR the ordering is: $V P->E U^{P_{-}}>F U_{-}>E P U$.

For both VAR systems, the least exogenous variable is EPU. Given how EPU is constructed, it is perhaps unsurprising that it might lag the other variables at a daily level in updating to reflect shocks to policy uncertainty, as the process of composing, editing and publishing print news articles might be expected to introduce a lag. ${ }^{16}$ Changes in financial uncertainty are strongly significant in Granger causing EPU in both VAR models. The variance premium is the most exogenous variable in each VAR, with no other variable Granger causing VP with statistical significance. The ordering of election uncertainty and financial uncertainty changes depending on the version of election uncertainty considered. The partisan uncertainty signal is statistically significant in Granger causing financial uncertainty and is a more exogenous variable than financial uncertainty according to the Granger causality results.

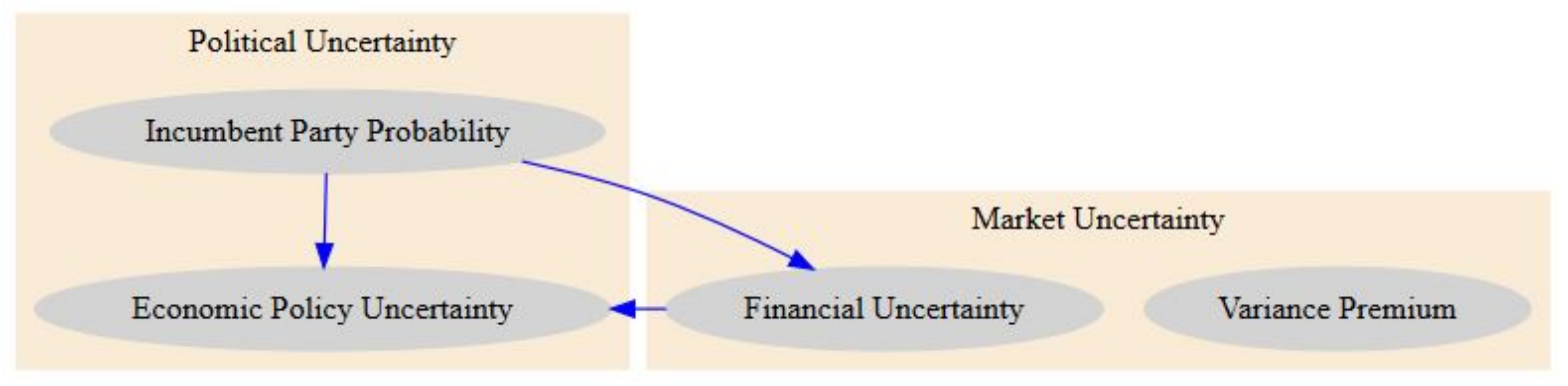

Figure 6: Granger Causality paths that are statistically significant in the $E U^{P}$ system panel VAR. $E U^{P}$ Granger causes financial uncertainty and election policy uncertainty. Financial uncertainty also Granger causes EPU.

\footnotetext{
${ }^{16}$ This expectation is supported by Strauß et al. (2016) who find that print news lags related market changes.
} 


\begin{tabular}{|c|c|c|}
\hline Equation /Excluded & $E U^{N P} \mathrm{VAR}$ & $E U^{P} \mathrm{VAR}$ \\
\hline & $\chi^{2}$ & $\chi^{2}$ \\
\hline \multicolumn{3}{|c|}{ EPU (Economic Policy Uncertainty) } \\
\hline$E U^{N P} / E U^{P}$ & $\begin{array}{c}0.19 \\
(0.24)\end{array}$ & $\begin{array}{c}0.62 \\
(0.43)\end{array}$ \\
\hline$F U$ & $\begin{array}{c}\mathbf{6 . 4 9}^{* * *} \\
(0.01)\end{array}$ & $\begin{array}{l}\mathbf{4 . 4 2}^{* *} \\
(0.04)\end{array}$ \\
\hline$V P$ & $\begin{array}{c}0.05 \\
(0.82)\end{array}$ & $\begin{array}{c}0.71 \\
(0.40)\end{array}$ \\
\hline$A L L$ & $\begin{array}{c}\mathbf{1 0 . 5 5 ^ { * * }} \\
(0.01)\end{array}$ & $\begin{array}{c}\mathbf{1 0 . 9 7 ^ { * * * }} \\
(0.01)\end{array}$ \\
\hline \multicolumn{3}{|c|}{$F U$ (Financial Uncertainty) } \\
\hline$E U^{N P} / E U^{P}$ & $\begin{array}{c}2.31 \\
(0.13)\end{array}$ & $\begin{array}{l}\mathbf{3 . 5 7 ^ { * }} \\
(0.06)\end{array}$ \\
\hline$E P U$ & $\begin{array}{c}0.10 \\
(0.75)\end{array}$ & $\begin{array}{c}0.02 \\
(0.90)\end{array}$ \\
\hline$V P$ & $\begin{array}{c}2.75 \\
(0.10)\end{array}$ & $\begin{array}{c}\mathbf{8 . 5 0}^{* * * *} \\
(0.00)\end{array}$ \\
\hline$A L L$ & $\begin{array}{c}5.92 \\
(0.12)\end{array}$ & $\begin{array}{l}\mathbf{9 . 3 2}^{* *} \\
(0.03)\end{array}$ \\
\hline \multicolumn{3}{|c|}{$E U$ (Election Uncertainty/Incumbent Party Probability } \\
\hline$E P U$ & $\begin{array}{c}1.18 \\
(0.28)\end{array}$ & $\begin{array}{c}2.38 \\
(0.12)\end{array}$ \\
\hline$F U$ & $\begin{array}{c}0.92 \\
(0.34)\end{array}$ & $\begin{array}{c}0.01 \\
(0.92)\end{array}$ \\
\hline$V P$ & $\begin{array}{c}\mathbf{6 . 4 1}^{* * *} \\
(0.10)\end{array}$ & $\begin{array}{c}0.25 \\
(0.62)\end{array}$ \\
\hline$A L L$ & $\begin{array}{l}\mathbf{6 . 4 4}^{*} \\
(0.09)\end{array}$ & $\begin{array}{l}2.60 \\
(0.46)\end{array}$ \\
\hline \multicolumn{3}{|c|}{$V P$ (Variance Premium) } \\
\hline$E P U$ & $\begin{array}{c}1.00 \\
(0.32)\end{array}$ & $\begin{array}{c}0.01 \\
(0.92)\end{array}$ \\
\hline$F U$ & $\begin{array}{c}0.56 \\
(0.45)\end{array}$ & $\begin{array}{c}0.06 \\
(0.81)\end{array}$ \\
\hline$E U^{N P} / E U^{P}$ & $\begin{array}{c}0.64 \\
(0.43)\end{array}$ & $\begin{array}{c}0.45 \\
(0.50)\end{array}$ \\
\hline$A L L$ & $\begin{array}{c}5.01 \\
(0.17)\end{array}$ & $\begin{array}{l}1.37 \\
(0.71)\end{array}$ \\
\hline
\end{tabular}

Table 4: Results of the Wald test for Granger causality in two panel VARs covering daily changes in the run up to seven elections. The two VARs differ in the measures used to capture election uncertainty. The first measure, $E U^{N P}$, is a non-partisan measure, the second, $E U^{P}$, corresponds to the win probability of the incumbent candidate's party. The partisan measure can be seen to have more power in Grangercausing financial uncertainty and results in a system where election uncertainty is exogenous in the sense that Granger causality of election uncertainty by a combination of the other variables is rejected ( $\mathrm{p}$ value of 0.46$)$. 


\subsection{Forecast error variance decomposition}

Table 5 displays the results of forecast error variance decomposition analysis from the daily panel VAR for each of the two candidate specifications based on $E U^{N P}$ and $E U^{P}$. Greater relevance of the incumbent party probability, $E U^{P}$, over the non-directional linear uncertainty measure, $E U^{N P}$, is clear from the results. $48.8 \%$ of daily variation in financial uncertainty changes, $F U$, are explained by changes in incumbent probability, compared with only $8.3 \%$ using the non-partisan election uncertainty measure. Furthermore, the partisan election uncertainty variable appears to be a better proxy for capturing the impact of policy uncertainty on financial uncertainty, as only $2.1 \%$ of the variation in $F U$ is explained by the EPU index in the partisan VAR and $0.5 \%$ in the non-partisan VAR. The partisan uncertainty measure can also be seen to capture $26.2 \%$ of the changes in the $E P U$ index in days leading up to the election; whereas the non-partisan election uncertainty signal only explains $4.5 \%$ of the changes to the EPU index. Overall, evidence clearly supports the importance of incumbent probability in engendering policy uncertainty.

For robustness, we test the impact of alternative identification orderings of the VAR system on our main findings. This is a crucial step in interpreting our results as we don't have a unique theoretical model for VAR identification ex-ante. Table 7 shows that the proportion of financial uncertainty, $F U$, explained by the changes in incumbent party probability, $E U^{P}$, is above $40 \%$ for all of the alternate VAR orderings. This corresponds to a factor of at least double the percentage obtained by using a non-partisan measure in the alternative VAR system in Table 8. The explanatory power of the EPU index is weak across all VAR orderings and both VAR systems. The importance of the incumbent probability relative to both a non-partisan uncertainty measure and the $E P U$ index is robust to the ordering of the VAR systems. In Appendix $\mathrm{C}$ we consider the impact of the other 


\begin{tabular}{cccccc}
\hline Response Variable & & \multicolumn{4}{c}{ Impulse Variable } \\
\cline { 1 - 3 } \cline { 4 - 5 } & & $V P$ & $F U$ & $E U^{N P}$ & $E P U$ \\
\hline$V P$ & 91.2 & 3.0 & 3.1 & 2.7 \\
$F U$ & 10.7 & 80.5 & $\mathbf{8 . 3}$ & $\mathbf{0 . 5}$ \\
$E U^{N P}$ & 5.6 & 10.3 & 82.7 & 1.4 \\
$E P U$ & 14.5 & 26.5 & $\mathbf{4 . 5}$ & 54.5 \\
\hline
\end{tabular}

Table 5: $E U^{N P}$ VAR: FEVD results after 10 time steps from a shock to the impulse variable, values show the percentage of the total explained forecast error variance of the response variable due to the shock to the impulse variable. The VAR is identified with variables listed in decreasing order of exogeneity. This ordering is based on the Granger causality results in Table 4 for a test for causality by "all" other variables. The variance premium, $V P$, is the most exogenous variable followed by financial uncertainty, $F U$; non-partisan election uncertainty, $E U^{N} P$ and economic policy uncertainty, $E P U$, which was found to be the most endogenous variable. Our main findings from this system VAR are the weak impact of $E U^{N P} \& E P U$ on $F U$, and the muted impact of $E U^{N P}$ on $E P U$ (when compared with the incumbent party probability results in Table 6 ). These are in bold, and are robust to changes in the panel VAR identification orderings in Table 8.

\begin{tabular}{cccccc}
\hline Response Variable & & \multicolumn{4}{c}{ Impulse Variable } \\
\cline { 1 - 5 } \cline { 5 - 6 } & & $V P$ & $E U^{P}$ & $F U$ & $E P U$ \\
\hline$E P$ & 90.8 & 8.4 & 0.3 & 0.4 \\
$E U^{P}$ & 3.3 & 91.0 & 1.7 & 4.0 \\
$F U$ & 8.8 & $\mathbf{4 8 . 8}$ & 40.3 & $\mathbf{2 . 1}$ \\
$E P U$ & 12.3 & $\mathbf{2 6 . 2}$ & 20.1 & 41.4 \\
\hline
\end{tabular}

Table 6: $E U^{P}$ VAR: FEVD results after 10 time steps from a shock to the impulse variable. The values are the percentage of the total explained forecast error variance of the response variable due to the shock to the impulse variable. The VAR is identified with variables listed in decreasing order of exogeneity in the first part of the table. This ordering is based on the Granger causality results in Table 4 for a test for causality by 'All' other variables. The variance premium, $V P$, is the most exogenous variable followed by incumbent party probability, $E U^{P}$; financial uncertainty, $F U$, and economic policy uncertainty, $E P U$, which was found to be the most endogenous variable. Our main results on the large impact of $E U^{P}$ on $F U$ and $E P U$, and the lack of impact of EPU on $F U$ are in bold and are robust to changes in the panel VAR identification orderings in Table 7. 


\begin{tabular}{|c|c|c|c|c|}
\hline \multirow{2}{*}{$\frac{\text { Response Variable }}{\text { Re-order } 1 .}$} & \multicolumn{4}{|c|}{ Impulse Variable } \\
\hline & $E U^{P}$ & $V P$ & $F U$ & $E P U$ \\
\hline$F U$ & 43.6 & 14.0 & 40.3 & 2.1 \\
\hline$E P U$ & 24.6 & 13.9 & 20.1 & 41.4 \\
\hline Re-order 2. & $V P$ & $F U$ & $E U^{P}$ & $E P U$ \\
\hline$F U$ & 8.8 & 40.2 & 48.9 & 2.1 \\
\hline$E P U$ & 12.3 & 19.9 & 26.4 & 41.4 \\
\hline Re-order 3. & $V P$ & $E U^{P}$ & $E P U$ & $F U$ \\
\hline$F U$ & 8.8 & 48.8 & 2.1 & 40.3 \\
\hline$E P U$ & 12.3 & 26.2 & 41.5 & 20.0 \\
\hline Re-order 4 & $E P U$ & $F U$ & $E U^{P}$ & $V P$ \\
\hline$F U$ & 3.0 & 43. & 43.0 & 11.1 \\
\hline$E P U$ & 53.9 & 22.6 & 16.0 & 7.5 \\
\hline
\end{tabular}

Table 7: $E U^{P}$ VAR Robustness analysis, FEVD analysis is repeated on the partisan election uncertainty, $E U^{P}$, panel VAR with four identification re-orderings: three pairwise ordering reversals of $V P$ and $E U$; $E U$ and $F U$; and $F U$ and $E P U$; as well as a complete reversal of orderings: $E P U ; F U ; E U ; V P$.

uncertainty variables on $F U$ and EPU using panel VAR results in different sample sizes around the election. The results suggest that there is a decreasing relevance of/attention on the election probabilities moving further from the election. This is consistent with the window of relevance suggested by the weekly volatility levels in Figure 5 . 


\begin{tabular}{|c|c|c|c|c|}
\hline \multirow{2}{*}{$\frac{\text { Response Variable }}{\text { Re-order } 1 .}$} & \multicolumn{4}{|c|}{ Impulse Variable } \\
\hline & $F U$ & $V P$ & $E U^{N P}$ & $E P U$ \\
\hline$F U$ & 85.5 & 5.7 & 8.3 & 0.5 \\
\hline$E P U$ & 29.5 & 11.5 & 4.5 & 54.5 \\
\hline Re-order 2. & $V P$ & $E U^{N P}$ & $F U$ & $E P U$ \\
\hline$F U$ & 10.7 & 17.5 & 71.3 & 0.5 \\
\hline$E P U$ & 14.5 & 5.3 & 25.7 & 54.5 \\
\hline Re-order 3. & $V P$ & $F U$ & $E P U$ & $E U^{N P}$ \\
\hline$F U$ & 10.7 & 80.5 & 0.4 & 8.4 \\
\hline$E P U$ & 14.5 & 26.5 & 55.0 & 4.0 \\
\hline Re-order 4. & $E P U$ & $E U^{N P}$ & $F U$ & $V P$ \\
\hline$F U$ & 1.6 & 17.2 & 75.5 & 5.7 \\
\hline$E P U$ & 63.7 & 4.6 & 28.2 & 3.5 \\
\hline
\end{tabular}

Table 8: $E U^{N P}$ VAR Robustness analysis, FEVD analysis is repeated on the non-partisan election uncertainty, $E U^{N P}$ panel VAR with four identification re-orderings: three pairwise ordering reversals of $V P \& F U ; F U \& E U$ and $E U \& E P U$ and a complete reversal of orderings: $E P U ; E U ; F U ; V P$.

\subsection{VAR impulse response functions}

VAR impulse response functions are displayed in Figures 7 and 8. Our main result is the significant impact of shocks to the incumbent party probability on financial uncertainty. Figure 8 (b.) shows that a positive shock to an incumbent party's election probability causes a negative change to financial uncertainty, decreasing financial uncertainty. The other significant relationship is displayed in Figure 8 (d.), which shows that a positive shock to financial uncertainty will drive an increase in the $E P U$ index.

In the partisan VAR the other significant relationships are shown in Figure 8 (h.) \& (i.), where shocks to $V P$ increase the probability of an incumbent being elected and decrease future $F U .{ }^{17}$ Shocks to $E P U$ also increase the probability of an incumbent being elected (Figure 8 (l.)).

For the non-partisan VAR, only shocks to financial uncertainty result in a significant

\footnotetext{
${ }^{17}$ The impact of shocks to the variance premium on financial uncertainty (Figure 8 (h.)) is potentially counter-intuitive. We discuss these results in more detail in Section 7.5.
} 
change to $E P U$. The impact of $E U^{N P}$ on $F U$ is negative in Figure 7 (b.), with financial uncertainty increasing as election uncertainty resolves. This effect may be capturing some of the same election-uncertainty impact as under the partisan VAR, but attenuated as the non-partisan uncertainty measure is correlated with the relevant incumbent uncertainty when the probability moves toward the incumbent. The effect is much weaker than in the corresponding partisan VAR, with the $90 \%$ confidence intervals on the IRF not crossing the $\mathrm{x}$-axis in the plot, indicating they are not significantly different to zero at the $90 \%$ confidence level. 
(a.)

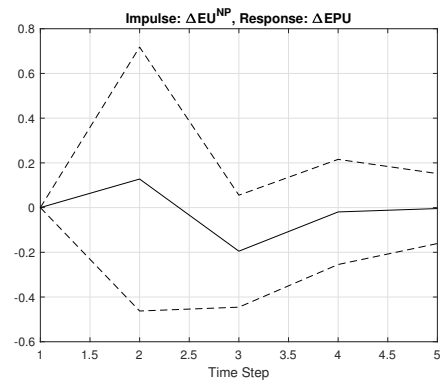

(d.)

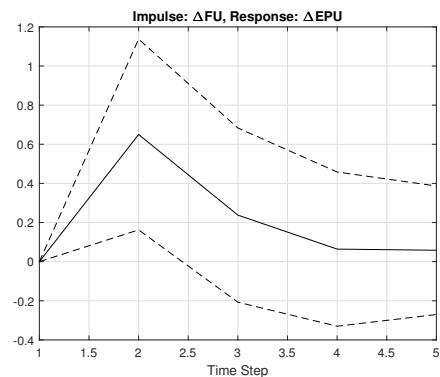

(g.)

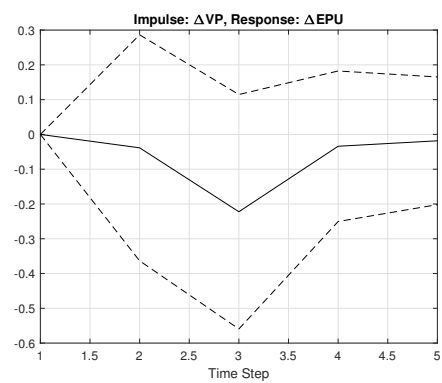

(j.)

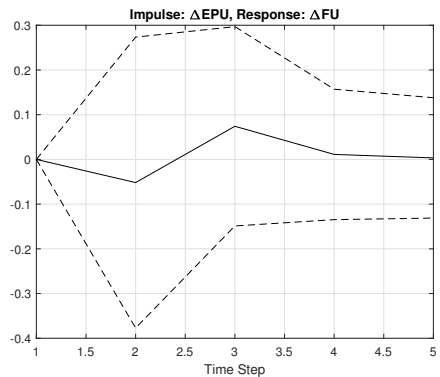

(b.)

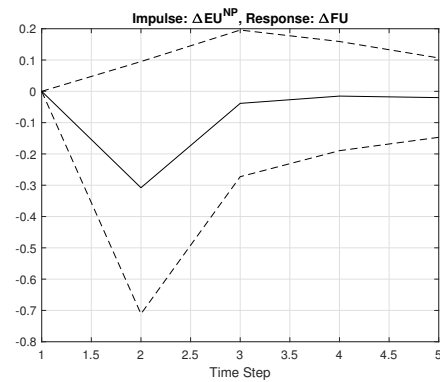

(e.)

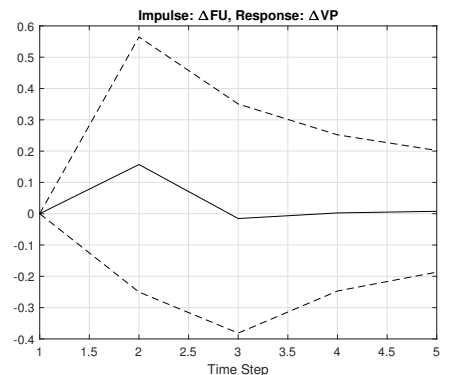

(h.)

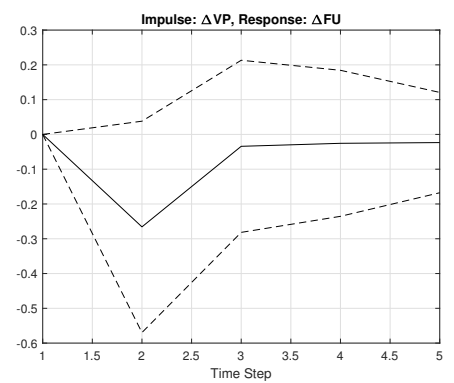

(k.)

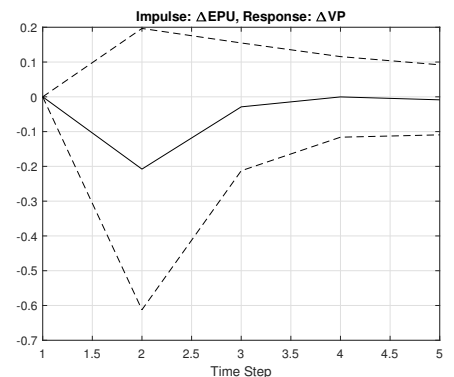

(c.)

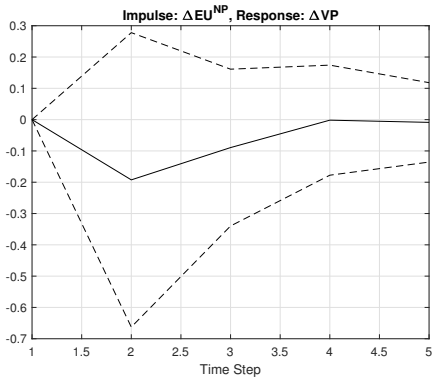

(f.)

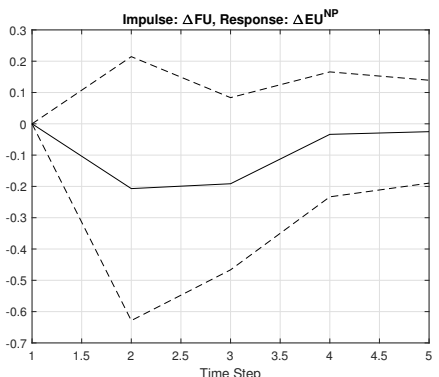

(i.)

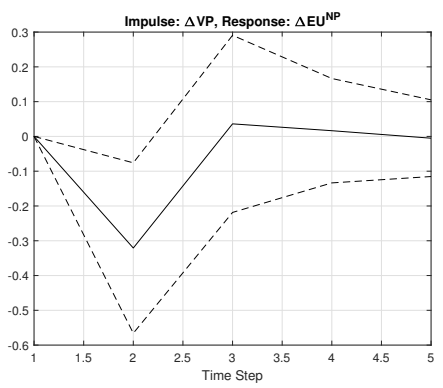

(1.)

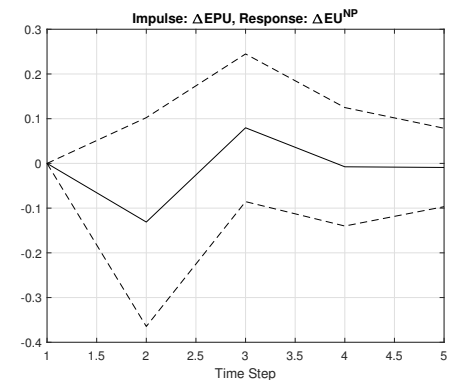

Figure 7: $E U^{N P}$ VAR: Impulse response functions for the panel VAR using non-directional Election Uncertainty, $E U^{N P}$, to capture election uncertainty. A one standard deviation shock is applied as the impulse variable in each case with responses also displayed in terms of standard deviations. The dashed lines give the $90 \%$ confidence intervals. Shocks to $E U$ have very limited impact on market uncertainty (both $F U \& V P$ ) and quite limited impact on $E P U$ relative to the results obtained using incumbent party probability, $E U^{P}$, as the election uncertainty measure, as shown in Figure 8 below. 
(a.)

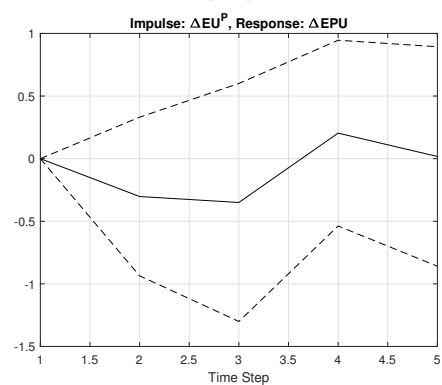

(d.)

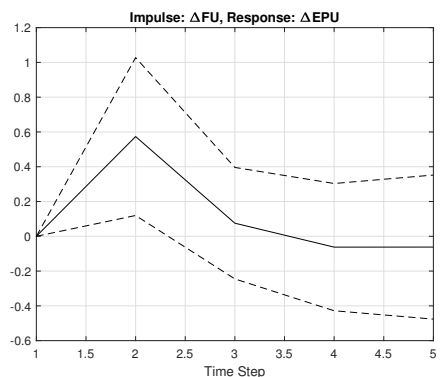

(g.)

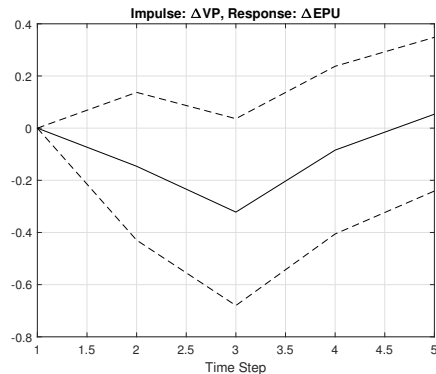

(j.)

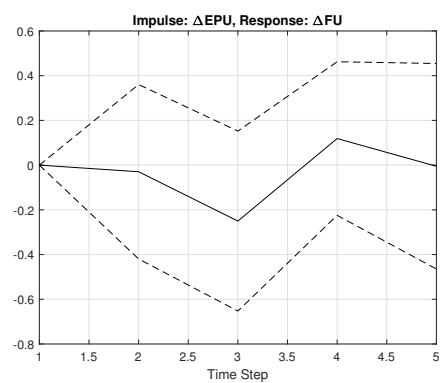

(b.)

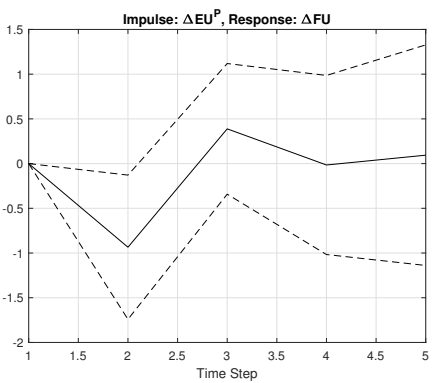

(e.)

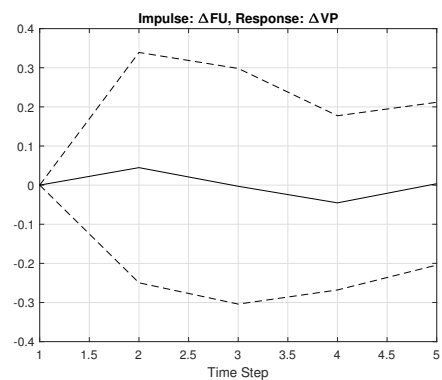

(h.)

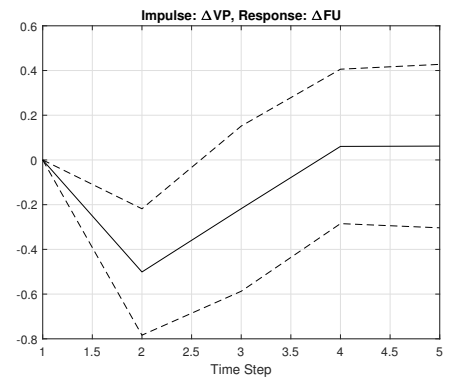

(k.)

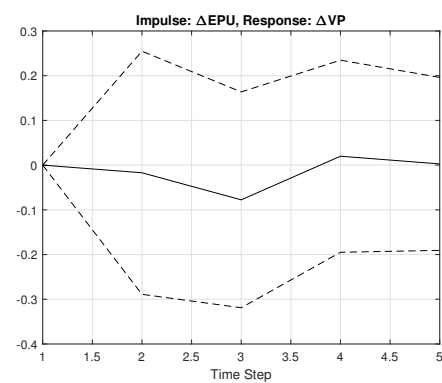

(c.)

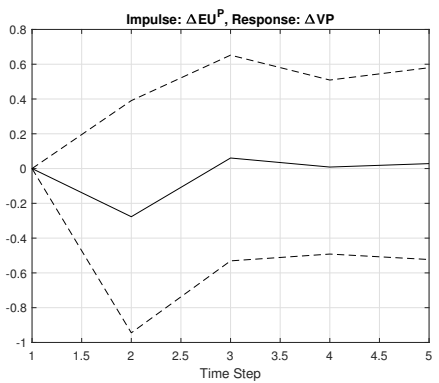

(f.)

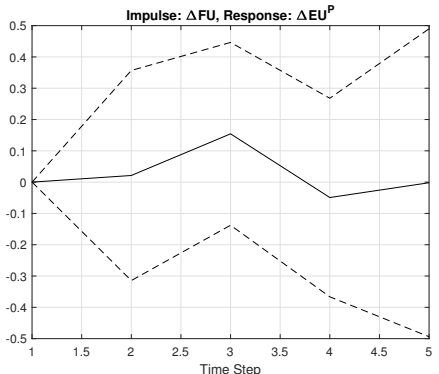

(i.)

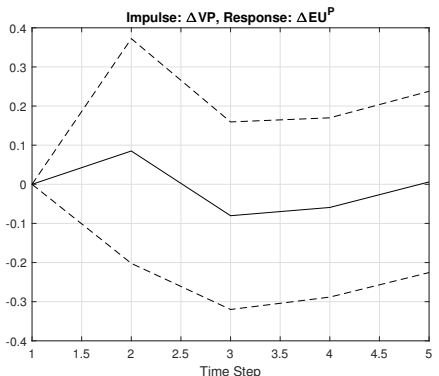

(1.)

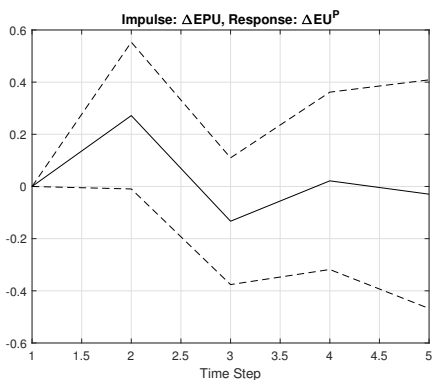

Figure 8: $E U^{P}$ VAR: Impulse response functions for the panel VAR using incumbent party probability, $E U^{P}$, to capture election uncertainty. A one standard deviation shock is applied as the impulse variable in each case with responses also displayed in terms of standard deviations. The dashed lines give the $90 \%$ confidence intervals. Positive shocks to $E U^{P}$ can be seen to decrease economic policy uncertainty in (a.). The same effect can be seen on financial uncertainty, $F U$, in (b.). Shocks to both the variance premium and financial uncertainty can be seen to increase economic policy uncertainty in (d.) and (g.) respectively. Shocks to economic policy uncertainty have very little additional impact on the system according to impulse response analysis - changes to policy uncertainty appear to be already captured by changes to the incumbent party probability. 


\subsection{Discussion}

Our main finding is that changes to incumbent party probability lead changes in financial uncertainty. Further, FEVD analysis suggests that these incumbent-party election uncertainty shocks drive a large portion of the changes to financial uncertainty in the final run-up to US presidential elections. According to our hypothesis, increased probability of a non-incumbent party candidate winning the election should lead to increased economic policy uncertainty. Our empirical results affirm this channel for election uncertainty impacting upon financial uncertainty.

Our panel VAR results suggest an ordering, with regard to when innovations in uncertainty around elections get reflected in the relevant election, policy, and financial uncertainty measures. Our results suggest the following temporal ordering: $V P->E U^{P}->F U-$ $>E P U$. However, while not the primary focus of our paper, findings with regard to the variance premium are in some ways unexpected. Based on Granger causality results, the most exogenous variable in the VAR system is the variance risk premium. This could be due to the size/efficiency of the market on S\&P 500 index options and their forwardlooking nature. ${ }^{18}$ Shocks to the variance premium, however, only explain small portions of the variation in the other variables, with the largest impact being on $E P U .{ }^{19}$ There is a counter-intuitive negative relationship between changes to $V P$ and future changes in $F U$. To investigate this relationship further we estimate a VAR over a sample of 6,839 days (from Jan-1990 to Feb-2017) using the three of the four uncertainty variables available for the full period: $V P, F U$ and $E P U$. The VAR coefficients for the large sample period are displayed in Table D.12. $F U$ has a positive coefficient on lagged $V P$, increases in

\footnotetext{
${ }^{18}$ There is an extensive literature on the predictive ability of option-implied information see e.g. (DeMiguel et al., 2013; Kempf et al., 2014; Kostakis et al., 2011).

${ }^{19}$ FEVD results in Section 7.3 attribute $12.3 \%$ of changes in EPU to shocks to $V P$.
} 
$V P$ lead to increases in subsequent $F U$. Furthermore, both $F U$ and $V P$ are negatively auto-correlated in the VAR, capturing their mean-reversion. The panel VAR coefficients over the election period in Table A.10 and the corresponding IRF analysis show that the negative auto-correlation for $F U$ disappears around elections, and that $F U$ has a negative exposure to increases in the variance risk premium during these times.

These findings suggest that the relationship between the financial uncertainty variables changes around elections. As the VIX is calculated using options with between 25 and 35 calendar days to expiry, it is not possible to pinpoint the exact period relevant to an increase in the variance premium within such a window. In non-election periods, a positive relationship between increased $V P$ and increased one-day lagged $F U$ is statistically significant; however around elections the dynamic appears to change. A potential criticism is that this difference is solely due to instability of the smaller sample VAR estimates. To test this we perform a boot-strapping experiment on the panel VAR estimation. We exclude the election years and randomly sample ${ }^{20}$ one hundred sets of seven 'pre-election' periods, including eight days of changes. Each election sample is selected from dates in the three non-election years preceding each of the seven election years. A panel VAR is estimated on the resulting seven election panels for each of the one hundred samples. A histogram of the resulting coefficient of $F U$ on lagged $V P$ is illustrated in Figure 9. None of the obtained coefficients are as extreme as that obtained in our election VAR (-0.5, see Table A.10). These results support that there is truly something different about this relationship around elections.

The reaction to increased tail uncertainty $(V P)$ around an election appears to be reduced volatility in the equity market, rather than the increased volatility evidenced

\footnotetext{
${ }^{20}$ We use the same Matlab random generator seed (mlfg6331_64) provided in the Mathworks user guide entry for the randstream command.
} 


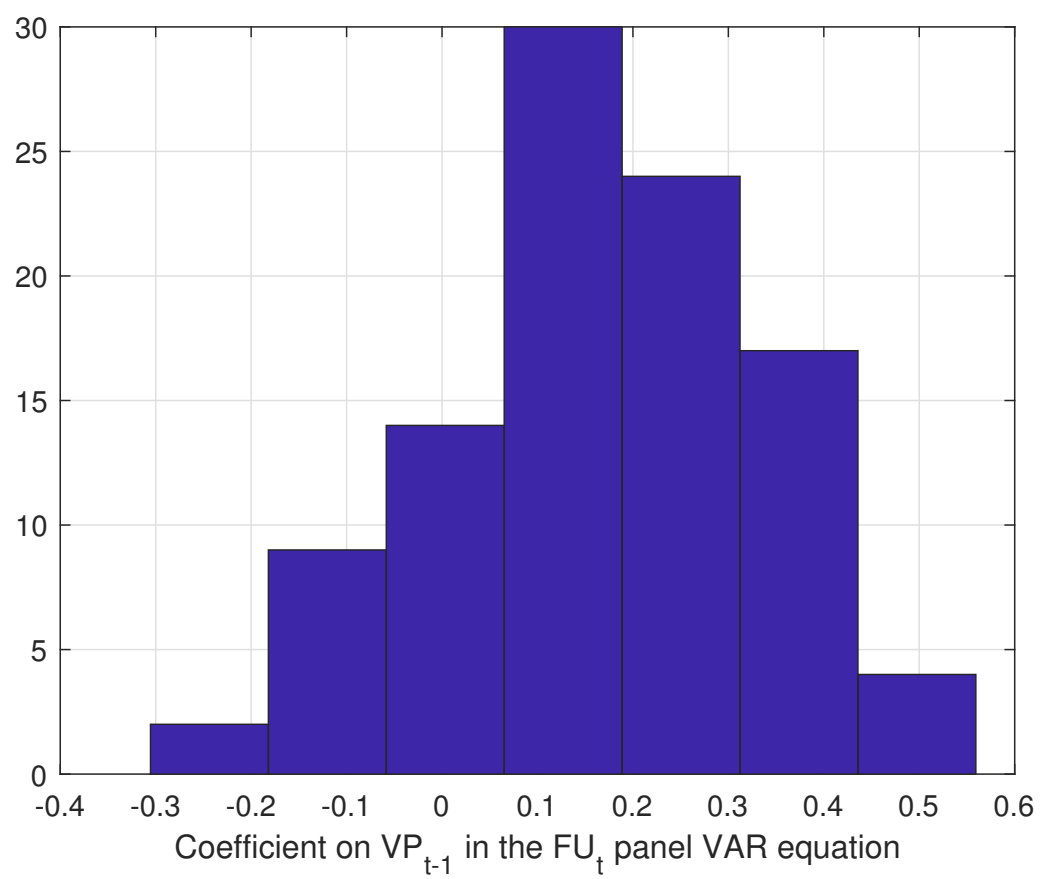

Figure 9: Histogram of the coefficient of $F U_{t}$ on $V P_{t-1}$ in a bootstrap experiment where a panel VAR is fit to 100 randomly selected election panels. The panels are selected from seven pre-election periods in the non-election years in the data sample. The coefficient of -0.5 in the true election panel VAR is shown in Table A.10. None of the 100 sampled panel VARs resulted in a coefficient this extreme, suggesting a very low probability that the result is due to instability of the VAR estimation.

over the full sample period. This could be due to a delay by market participants in acting on the increased crash risk due to its association with the fixed future date of the election and/or it could represent market participants moving to options and futures markets to hedge the jump component of the election risk of the index. This is also consistent with $V P$ not being mean-reverting in the election VAR, as $V P$ shocks persist as they are linked with a specific future election date. We explore the economic implications of this relationship further in the following section.

\subsection{Economic Significance}

The predictability of changes in volatility in the system has potential economic significance, for example to option traders and volatility swap traders. Changes to the incumbent-party probability from predictive markets have the most explanatory power on future realized volatility, with changes in the variance risk premium also leading changes 
in financial uncertainty. Based on our findings it would be rational to sell put options short-term in the run-up to elections when both the variance risk premium (resulting in higher option prices but not increased short-term volatility) and incumbent-party probability chances of re-election increase (reducing future realized volatility). Under these conditions it would also be rational to sell a variance swap with payoff $=\sigma_{\text {realized }}^{2}-\sigma_{\text {implied }}^{2}$.

While the opportunity set for trades is quite limited in our sample we evaluate an illustrative trading scheme using data from Option Metrics for the final six election periods for which option data are available. We consider the strategy of an option trader, informed by our findings, who writes an at-the-money put option when the changes in both the variance premium and the incumbent probability are positive. ${ }^{21}$ We use European options on the S\&P500 (traded on the CBOE), and select options that span the election, expiring on the third Friday of the election month. As our analysis is at the daily frequency, all trades are for a single day with positions covered the next day by purchasing an identical option of the same strike and expiry date. All options are bought at the ask price and sold at the bid price incurring the full bid/ask spread on each trade. As no capital investment is required to sell puts, returns are calculated as a return on margin, where the margin is approximated by a representative brokerage rule of $100 \%$ of the bid price for the option plus $20 \%$ of the underlying strike.

In total 13 options trades are entered into out of 48 candidate days. For comparison, we also track returns to selling ATM puts in the other 35 days in the sample. Results for both schemes are reported in Table 9 . The average returns for the 35 days without the trading condition are negative, this is not surprising as the strategy is incurring a full bid/ask spread in a single day. The mean return for the 13 trades that meet the trigger

\footnotetext{
${ }^{21}$ Puts are selected as under a widely documented leverage effect reduced equity index volatility is coupled with an increase in expected index returns (see e.g., Moreira and Muir, 2019).
} 


\begin{tabular}{|c|c|c|c|c|}
\hline Trade Trigger & No. Trades & $\begin{array}{c}\text { Mean } \\
(\%)\end{array}$ & $\begin{array}{l}\text { Std } \\
(\%)\end{array}$ & $\begin{array}{c}\text { Sharpe } \\
\text { (Annual) }\end{array}$ \\
\hline 1. $\left(E U^{P}>0 \& V P>0\right)$ & 13 & 0.97 & 2.35 & 6.56 \\
\hline 2. $\quad !\left(E U^{P}>0 \& V P>0\right)$ & 35 & -0.42 & 5.36 & -2.86 \\
\hline
\end{tabular}

Table 9: Analysis of the trading returns for a scheme that sells at the money put options when changes in the incumbent party probability and the variance premium are both positive. The second set of results are for selling at the money put options in the days in which the conditions do not hold.

conditions is positive (almost 1\% daily return), with an annualized Sharpe ratio of 6.56 . We also consider a strategy that sells options on days that the relevant conditions are triggered and invests in the risk-free rate in non-triggered days. This allows us to test the difference in return performance for the two strategies over a common period. We test the difference in Sharpe ratios for the two strategies using the methodology of Jobson and Korkie (1981), corrected as per Memmel (2003). The improvement in Sharpe ratio through using a condition to time option selling based off positive changes in $E U^{P}$ and $V P$ is statistically significant at the $10 \%$ level ( $\mathrm{p}$ value $=0.088$ ).

These illustrative trade results show that, consistent with our panel VAR framework findings, increases in the variance premium and the incumbent party probability are associated with a lagged decrease in put option prices. Trading this information on days when these conditions hold results in an average net daily return of almost $1 \%$. Option traders or market makers may want to factor in the potential impact of these returns to selling puts on their existing strategies on days in which these conditions hold in the run up to US Presidential elections. The net result of traders selling these options would be to increase the supply, decreasing the price received for the options and resulting in a reduction in the associated implied variance premium. 


\section{Conclusions}

To our knowledge, there is little research that investigates the mechanism through which election uncertainty impacts economic policy uncertainty (EPU) and financial market uncertainty. Further, there are relatively few studies that examine election uncertainty with time-series data. In order to investigate the relationship between election uncertainty, economic-policy uncertainty, and market uncertainty, we perform a prediction-market analysis that leverages multiple days of outcome probability changes in the run up to US presidential elections.

We hypothesize the importance of outcome probabilities for the incumbent party of the current president, $E U^{P}$, impacting policy uncertainty. Our panel VAR results confirm this. Using a partisan measure of uncertainty versus a nonpartisan version, $48.8 \%$ of the variation in economic policy uncertainty is explained by changes in $E U^{P}$ versus just $8.3 \%$ using a non-partisan election uncertainty variable. Our findings suggest it is uncertainty regarding the election likelihood of a replacement party of the executive branch of government that drives policy uncertainty during US presidential election seasons. The key role of changes in the election probability of the incumbent president's party is further confirmed by our finding that when using $E U^{P}$ in the VAR system, the impact of the EPU index of Baker et al. (2016) weakens, providing little additional explanatory power over $E U^{P}$ in explaining financial uncertainty in the final stage of US elections.

Our findings confirm the importance of election-driven policy uncertainty to financial uncertainty. These results will be of particular interest to scholars concerned about the impact of election uncertainty on financial markets; as well as to volatility traders in the final days of election campaigns seeking to interpret how changes in outcome probability may impact on future realized volatility levels. 
Abrigo, M. R., Love, I., et al., 2016. Estimation of panel vector autoregression in Stata. Stata Journal 16 (3), 778-804.

Andrews, D. W., Lu, B., 2001. Consistent model and moment selection procedures for GMM estimation with application to dynamic panel data models. Journal of Econometrics 101 (1), 123-164.

Baker, S. R., Bloom, N., Davis, S. J., 2016. Measuring economic policy uncertainty. The Quarterly Journal of Economics 131 (4), 1593-1636.

Bakshi, G., Madan, D., 2006. A theory of volatility spreads. Management Science 52 (12), $1945-1956$.

Bekaert, G., Engstrom, E., 2017. Asset return dynamics under habits and bad environment-good environment fundamentals. Journal of Political Economy 125 (3), $713-760$.

Bekaert, G., Engstrom, E. C., Xu, N. R., 2019. The time variation in risk appetite and uncertainty. Tech. rep., National Bureau of Economic Research.

Bekaert, G., Hoerova, M., 2014. The VIX, the variance premium and stock market volatility. Journal of Econometrics 183 (2), 181-192.

Bekaert, G., Hoerova, M., Duca, M. L., 2013. Risk, uncertainty and monetary policy. Journal of Monetary Economics 60 (7), 771-788.

Berg, J., Forsythe, R., Nelson, F., Rietz, T., 2008. Results from a dozen years of election futures markets research. Handbook of experimental economics results 1, 742-751.

DeMiguel, V., Plyakha, Y., Uppal, R., Vilkov, G., 2013. Improving portfolio selection 
using option-implied volatility and skewness. Journal of Financial and Quantitative Analysis 48 (6), 1813-1845.

Drechsler, I., 2013. Uncertainty, time-varying fear, and asset prices. The Journal of Finance 68 (5), 1843-1889.

Garman, M. B., Klass, M. J., 1980. On the estimation of security price volatilities from historical data. Journal of Business, 67-78.

Goodell, J. W., McGroarty, F., Urquhart, A., 2015. Political uncertainty and the 2012 US presidential election: A cointegration study of prediction markets, polls and a stand-out expert. International Review of Financial Analysis 42, 162-171.

Goodell, J. W., Vähämaa, S., 2013. US presidential elections and implied volatility: The role of political uncertainty. Journal of Banking and Finance 37 (3), 1108-1117.

Hamilton, J. D., 1994. Time Series Analysis. Vol. 2. Princeton university press Princeton.

Jobson, J. D., Korkie, B. M., 1981. Performance hypothesis testing with the Sharpe and Treynor measures. The Journal of Finance 36 (4), 889-908.

Kelly, B., Pástor, L., Veronesi, P., 2016. The price of political uncertainty: Theory and evidence from the option market. The Journal of Finance.

Kempf, A., Korn, O., Saßning, S., 2014. Portfolio optimization using forward-looking information. Review of Finance 19 (1), 467-490.

Knight, B., 2006. Are policy platforms capitalized into equity prices? Evidence from the Bush/Gore 2000 presidential election. Journal of Public Economics 90 (4-5), 751-773.

Knight, F. H., 1921. Risk, uncertainty and profit. New York: Hart, Schaffner and Marx. 
Kostakis, A., Panigirtzoglou, N., Skiadopoulos, G., 2011. Market timing with optionimplied distributions: A forward-looking approach. Management Science 57 (7), 12311249.

Longstaff, F. A., Pan, J., Pedersen, L. H., Singleton, K. J., 2011. How sovereign is sovereign credit risk? American Economic Journal: Macroeconomics 3 (2), 75-103.

Lütkepohl, H., 2005. New introduction to multiple time series analysis. Springer Science \& Business Media.

Martin, I., 2017. What is the expected return on the market? The Quarterly Journal of Economics 132 (1), 367-433.

Mattozzi, A., 2008. Can we insure against political uncertainty? evidence from the US stock market. Public Choice 137 (1-2), 43-55.

McGee, R. J., McGroarty, F., 2017. The risk premium that never was: A fair value explanation of the volatility spread. European Journal of Operational Research 262 (1), $370-380$.

Memmel, C., 2003. Performance hypothesis testing with the Sharpe ratio. Finance Letters $1(1)$.

Moreira, A., Muir, T., 2019. Should long-term investors time volatility? Journal of Financial Economics 131 (3), 507-527.

Pástor, L., Veronesi, P., 2013. Political uncertainty and risk premia. Journal of Financial Economics 110 (3), 520-545.

Prokopczuk, M., Simen, C. W., 2014. The importance of the volatility risk premium for volatility forecasting. Journal of Banking and Finance 40, 303-320. 
Rhode, P. W., Strumpf, K. S., 2004. Historical presidential betting markets. The Journal of Economic Perspectives 18 (2), 127-141.

Sims, C. A., 1972. Money, income, and causality. The American Economic Review 62 (4), $540-552$.

Sims, C. A., 1981. An autoregressive index model for the US 1948-1975. Large-Scale Macro-Econometric Models, Amsterdam: North-Holland 1981, 283-327.

Snowberg, E., Wolfers, J., Zitzewitz, E., 2007. Partisan impacts on the economy: evidence from prediction markets and close elections. The Quarterly Journal of Economics $122(2), 807-829$.

Snowberg, E., Wolfers, J., Zitzewitz, E., 2011. How prediction markets can save event studies. Tech. rep., National Bureau of Economic Research.

Strauß, N., Vliegenthart, R., Verhoeven, P., 2016. Lagging behind? Emotions in newspaper articles and stock market prices in the netherlands. Public Relations Review 42 (4), $548-555$.

Todorov, V., 2009. Variance risk-premium dynamics: The role of jumps. The Review of Financial Studies 23 (1), 345-383.

Yang, D., Zhang, Q., 2000. Drift-independent volatility estimation based on high, low, open, and close prices. The Journal of Business 73 (3), 477-492. 


\section{Appendix A. VAR estimation \& stability}

\begin{tabular}{|c|c|c|c|c|}
\hline & $V P_{t-1}$ & $E U_{t-1}^{P}$ & $F U_{t-1}$ & $E P U_{t-1}$ \\
\hline \multicolumn{5}{|c|}{4 Variable VAR } \\
\hline$F U_{t}$ & $\begin{array}{l}-0.501^{* * *} \\
(0.004)\end{array}$ & $\begin{array}{l}-0.935^{*} \\
(0.059)\end{array}$ & $\begin{array}{l}0.189 \\
(0.408)\end{array}$ & $\begin{array}{l}-0.030 \\
(0.902)\end{array}$ \\
\hline$E P U_{t}$ & $\begin{array}{l}-0.146 \\
(0.400)\end{array}$ & $\begin{array}{l}-0.302 \\
(0.432)\end{array}$ & $\begin{array}{l}0.573^{* *} \\
(0.035)\end{array}$ & $\begin{array}{l}-0.035 \\
(0.847)\end{array}$ \\
\hline$V P_{t}$ & $\begin{array}{l}0.095 \\
(0.591)\end{array}$ & $\begin{array}{l}-0.277 \\
(0.501)\end{array}$ & $\begin{array}{l}0.045 \\
(0.805)\end{array}$ & $\begin{array}{l}-0.017 \\
(0.918)\end{array}$ \\
\hline$E U_{t}^{P}$ & $\begin{array}{l}0.085 \\
(0.620)\end{array}$ & $\begin{array}{l}-0.447 \\
(0.172)\end{array}$ & $\begin{array}{l}0.0212 \\
(0.916)\end{array}$ & $\begin{array}{l}0.271 \\
(0.123)\end{array}$ \\
\hline
\end{tabular}

Table A.10: VAR coefficients for an event window consisting of eight days for each of the seven elections (56 in total).

(a.)

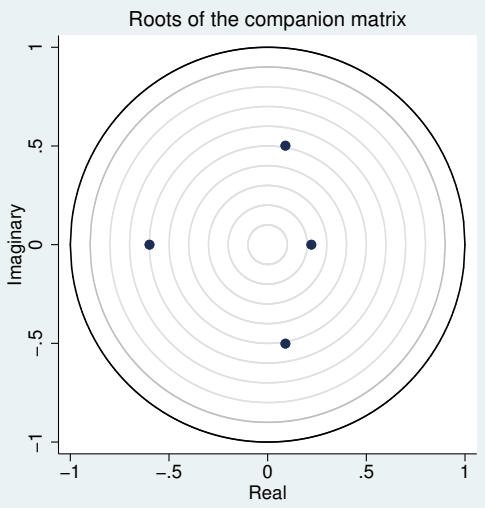

(b.)

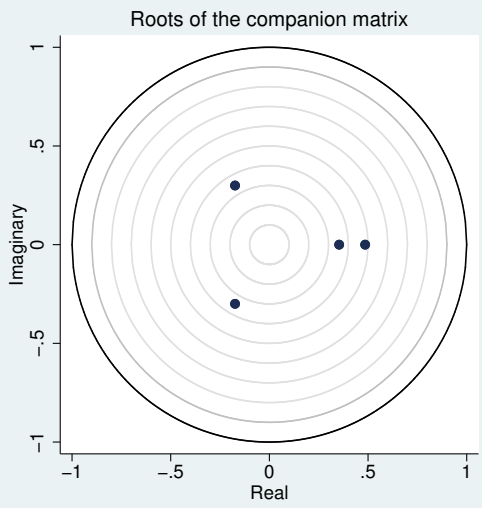

Figure A.10: Stability plots for (a.) the $E U^{P}$ VAR and (b.) the $E U^{N P}$ VAR. All eigenvalues of the companion matrices are well within the unit circle, indicating that both VAR estimations are stable.

\section{Appendix B. Excluding the financial crisis}

In this section we repeat the main analysis excluding the 2008 election coincident with the financial crisis. Granger causality results indicate that $E U^{P}$ is significant in causing $F U$ in the sample of the other six non-crisis elections with a $\chi^{2}$ value of 3.4 (P-value 0.06). The variance premium was also significant in Granger causing $F U$, with a $\chi^{2}$ value 
of 8.1 (P-value 0.00). All other causation relationships were insignificant at the $10 \%$ level, with $F U$ Granger causing EPU at the $13 \%$ confidence level and all other relationships having P-values of 0.2 or higher. FEVD analysis on the 6 non-crisis elections showed that $29.8 \%$ of $F U$ and $29.1 \%$ of $E P U$ are explained by changes in $E U^{P}$ in the VAR system. The importance of changes in the incumbent party in the run up to elections in terms of impact on financial uncertainty and policy uncertainty are therefore not dependent on the inclusion of the financial crisis period. 


\section{Appendix C. Election sample window}

\begin{tabular}{|c|c|c|c|c|}
\hline \multirow[t]{2}{*}{ Response Variable } & \multicolumn{4}{|c|}{ Impulse Variable } \\
\hline & $E U^{P}$ & $F U$ & $V P$ & $E P U$ \\
\hline \multicolumn{5}{|c|}{7 Day sample window } \\
\hline$F U$ & 50.9 & 30.9 & 15.8 & 2.5 \\
\hline$E P U$ & 41.6 & 17.3 & 21.4 & 19.8 \\
\hline \multicolumn{5}{|c|}{8 Day sample window } \\
\hline$F U$ & 48.8 & 40.3 & 8.8 & 2.1 \\
\hline$E P U$ & 26.2 & 20.1 & 12.3 & 41.4 \\
\hline \multicolumn{5}{|c|}{9 Day sample window } \\
\hline$F U$ & 33.0 & 63.5 & 1.6 & 1.8 \\
\hline$E P U$ & 10.2 & 14.4 & 7.0 & 68.5 \\
\hline \multicolumn{5}{|c|}{10 Day sample window } \\
\hline$F U$ & 19.7 & 76.4 & 1.5 & 2.4 \\
\hline$E P U$ & 6.3 & 10.8 & 5.7 & 77.2 \\
\hline \multicolumn{5}{|c|}{20 Day sample window } \\
\hline$F U$ & 0.0 & 93.0 & 3.5 & 3.6 \\
\hline$E P U$ & 2.1 & 0.7 & 0.4 & 96.8 \\
\hline \multicolumn{5}{|c|}{30 Day sample window } \\
\hline$F U$ & 0.5 & 94.8 & 1.7 & 2.9 \\
\hline$E P U$ & 1.1 & 1.3 & 1.0 & 96.7 \\
\hline
\end{tabular}

Table C.11: Robustness checks varying the sample window duration for analysis. The percentage of changes in financial uncertainty explained by changes in partisan election uncertainty range from $51 \%$ down to $19.7 \%$ as the sample window is extended back from seven business days to ten business days. This drops to $0 \%$ for a sample including up to twenty days out. Changes in the variance premium appear to have a shorter window of relevance around the election with their impact on election uncertainty and policy uncertainty dropping rapidly beyond seven business days before the election. 


\section{Appendix D. 3-variable VAR}

\begin{tabular}{llll}
\hline & $V P_{t-1}$ & $F U_{t-1}$ & $E P U_{t-1}$ \\
\hline$V P_{t}$ & $-0.263^{* * *}$ & $-0.046^{* * *}$ & $-0.003^{*}$ \\
& $(0.000)$ & $(0.002)$ & $(0.087)$ \\
$F U_{t}$ & $0.163^{* * *}$ & $-0.132^{* * *}$ & $0.005^{* * *}$ \\
& $(0.000)$ & $(0.000)$ & $(0.000)$ \\
$E P U_{t}$ & $0.175^{*}$ & $-0.546^{* * *}$ & $-0.319^{* * *}$ \\
& $(0.062)$ & $(0.000)$ & $(0.000)$ \\
\hline
\end{tabular}

Table D.12: VAR coefficients for a three-variable VAR including daily changes in financial uncertainty, $F U$; the variance premium, $V P$; and economic policy uncertainty, EPU. The period covered is from Jan-1990 to Feb-2017 and includes a sample of 6,839 days.. 


\begin{tabular}{|c|c|}
\hline Equation/Excluded & $\chi^{2}$ \\
\hline \multicolumn{2}{|c|}{$F U$ (Financial Uncertainty) } \\
\hline$V P$ & $\begin{array}{c}259.98^{* * *} \\
(0.000)\end{array}$ \\
\hline$E P U$ & $\begin{array}{c}14.85^{* * *} \\
(0.000)\end{array}$ \\
\hline$A L L$ & $\begin{array}{c}272.76^{\text {*** }} \\
(0.000)\end{array}$ \\
\hline \multicolumn{2}{|c|}{$V P$ (Variance Premium) } \\
\hline$E P U$ & $\begin{array}{c}2.94^{*} \\
(0.087)\end{array}$ \\
\hline$F U$ & $\begin{array}{c}10.01^{* * *} \\
(0.002)\end{array}$ \\
\hline$A L L$ & $\begin{array}{c}13.10^{* * *} \\
(0.001)\end{array}$ \\
\hline \multicolumn{2}{|c|}{ EPU (Economic Policy Uncertainty) } \\
\hline$F U$ & $\begin{array}{c}23.86^{* * *} \\
(0.000)\end{array}$ \\
\hline$V P$ & $\begin{array}{c}3.48^{*} \\
(0.06)\end{array}$ \\
\hline$A L L$ & $\begin{array}{c}24.22^{* * *} \\
(0.000)\end{array}$ \\
\hline
\end{tabular}

Table D.13: Granger Causality results for a three variable VAR using daily changes in financial uncertainty, $F U$, the variance premium, $V P$ and economic policy uncertainty, $E P U$. The period covered is from Jan-1990 to Feb-2017 and includes a sample of 6,839 days. 